\title{
Examining the effect of chronic intranasal oxytocin administration on the neuroanatomy and behavior of three autism-related mouse models
}

\author{
Zsuzsa Lindenmaier ${ }^{1,2}$, Jacob Ellegood ${ }^{1}$, Monique Stuive ${ }^{1}$, Kaitlyn \\ Easson $^{1}$, Jane Foster ${ }^{3}$, Evdokia Anagnostou ${ }^{4}$, Jason P. Lerch ${ }^{1,2,5}$ \\ ${ }^{1}$ Mouse Imaging Centre, Hospital for Sick Children, \\ Toronto, Ontario, Canada \\ ${ }^{2}$ Department of Medical Biophysics, University of Toronto, \\ Toronto, Ontario, Canada \\ ${ }^{3}$ Department of Psychiatry and Behavioral Neurosciences, McMaster \\ University, St.Joseph's Healthcare, Hamilton, Ontario, Canada \\ ${ }^{4}$ Autism Research Center, Holland Bloorview Kids Rehabilitation \\ Hospital, Toronto, Canada \\ ${ }^{5}$ Wellcome Centre for Integrative NeuroImaging, \\ University of Oxford, Oxford, United Kingdom
}

\section{Abstract}

Due to the heterogeneous nature of autism, treatment will likely only ameliorate symptoms in a subset of patients. To determine what might contribute to response susceptibility, we chronically treated the 16p11.2 deletion, Shank3 (exon 4-9) knockout, and Fmr1 knockout mouse models with intranasal oxytocin. Intranasal oxytocin $(0.6 \mathrm{IU})$ was administered daily, for 28 days, starting at 5 weeks of age. The behavior of the mice was assessed in multiple domains: repetitive behaviors (as assessed by grooming), sociability (three chamber sociability task), anxiety and hyperactivity (open field), and learning and motor coordination (rotarod). The mice underwent three in vivo longitudinal MRI scans and a final high resolution ex vivo scan to assess the changes in neuroanatomy in response to treatment. No significant effect of treatment was found on social behavior in any of the strains, although a significant effect of treatment was found in the Fmr1 mouse, with treatment normalizing a grooming deficit. No other treatment effect on behavior was observed that survived multiple comparisons correction. Treatment effect on the neuroanatomy did not reach significance. Overall, chronic treatment with oxytocin had limited effects on the three mouse models related to autism, and no promising pattern of response susceptibility emerged. 


\section{Introduction}

Autism spectrum disorder (ASD) is a very heterogeneous neurodevelopmental disorder, characterized by impaired social communication and repetitive behaviors. To date, there is no pharmacological treatment to improve the social/communication deficits in autism patients (Anagnostou et al. (2012); de la Torre-Ubieta et al. (2016)). One promising pharmacological treatment for these social communication deficits is oxytocin.

Oxytocin is a neuromodulator, used in humans commercially to induce labor, but is known for its social effects. Clinical trials have shown that oxytocin induces anxiolytic and anti-depressant effects, to promote social recognition (Benarroch (2013)). Oxytocin also leads to enhanced processing of social stimuli, by increased ingroup trust, increased emotion recognition, and increased eye contact(Gordon et al. (2013)). Oxytocin has been shown to increase activity in brain structures involved in processing socially meaningful stimuli (Andari et al. (2020, 2016); Aoki et al. (2014); Aoki and Yamasue (2015); Benner et al. (2021); Domes et al. (2013); Gordon et al. (2013); Watanabe et al. (2014, 2015)). Oxytocin also has numerous brain targets, including but not limited to the amygdala, hippocampus, hypothalamus, and nucleus accumbens (Quintana et al. (2019)). Therefore, it may be postulated that treatment with oxytocin would normalize social behaviors and memory, while decreasing anxiety and parasympathetic activation (fear/stress) (Benarroch (2013); Guastella and Hickie (2016)).

Oxytocin treatment has recently also been considered in autism for reasons other than its social effects (Anagnostou et al. (2012); de la Torre-Ubieta et al. (2016); Guastella and Hickie (2016)). Namely, the oxytocin gene has shown aberrations in genetic association studies of ASD (Bittel et al. (2006); Gregory et al. (2009); Jacob et al. (2007); Sebat et al. (2007)); ; a reduction of oxytocin mRNA has been shown in the temporal cortices of individuals with ASD (Gregory et al. (2009)); variation in the oxytocin receptor $(O X T R)$ gene differentially effects the neuroendophenotype of youth with ASD (Hernandez et al. (2017)); and, abnormal oxytocin blood levels have also been measured in individuals with ASD (Andari et al. (2020); Green et al. (2001); Modahl et al. (1998)). All of these instances point to the potential for oxytocin to improve aspects of ASD.

A number of existing studies have investigated the effects of oxytocin in autism and related animal models. In mice, knockout of the oxytocin receptor caused a resistance to change and social deficits (behaviors characteristic of autism), which was normalized after acute treatment with oxytocin $(0.5 \mathrm{ng} / 2 \mu \mathrm{L} /$ mouse ICV) (Sala et al. (2011)). Subchronic oxytocin administration $(1.0 \mathrm{mg} / \mathrm{kg}$ i.p.) in strains of mice with social deficits $(\mathrm{BALB} / \mathrm{cByJ}$ ) or repetitive behaviors (C58/J mice) increased sociability in both strains (Teng et al. (2013)). Social behavior in a genetic mouse model of autism (Cntnap2) was restored by oxytocin treatment $(1.0 \mathrm{mg} / \mathrm{kg}$ i.p.)(Peñagarikano et al. (2015)). Multiple studies have shown an increase in emotion recognition abilities and increased ability to process socially relevant cues in animal models administered a single dose of oxytocin (i.e. $0.25 \mu \mathrm{g} / 5 \mu \mathrm{L}$ and $0.5 \mu \mathrm{g} / 5 \mu \mathrm{L}$ i.n.)( Graustella and MacLeod (2012); Guastella and Hickie (2016); Huang et al. (2014)).

However, there are several shortcomings in our current understanding of oxytocin as a potential pharmacological treatment for ASD. First, although there is an extensive wealth of literature on the significant acute effects of oxytocin, knowledge 
of the effects of chronic administration is sparse (Guastella and Hickie (2016)).For example, only three clinical trials found improvements with chronic administration, all with relatively low sample sizes $(\mathrm{n}=18,19,30)$ (Anagnostou et al. (2012); Watanabe et al. (2015); Yatawara et al. (2016)). Given the lifelong nature of the disorder and its symptoms, chronic treatment is likely the only way amelioration of autism symptoms would occur.

Moreover, there is a gap in our knowledge surrounding oxytocin's effects on the brain. A number of neuroimaging studies investigating oxytocin's effect on neural activity during behavioral tasks found enhanced brain activity predictive of behavioral effects due to treatment (Andari et al. (2020, 2016); Aoki et al. (2014); Aoki and Yamasue (2015); Benner et al. (2021); Gordon et al. (2013); Watanabe et al. $(2014,2015))$. But these effects are from a number of regions across the brain, including the amygdala, the anterior cingulate cortex, the anterior insula, the hippocampus, the medial prefrontal cortex, the striatum, and others. Many of these studies have low sample sizes ( $<40$ participants) and were performed using acute oxytocin administration, leaving our understanding of where the drug acts after administration limited, despite knowing where oxytocin receptors are located (Benarroch (2013); Quintana et al. (2019)) and our understanding of some of the effects oxytocin has on neural activity in the context of social behavior.

This problem is further exacerbated by the pharmacology of oxytocin. The neuropeptide is too large to cross the blood brain barrier and has a very short half-life (Neumann et al. (2013)). Therefore, an administration method is needed that quickly and directly allows oxytocin to enter the brain. Though methods like intracerebroventricular (ICV) infusion and peripheral injections have been used in animal models, there is a need for a method that is easily employed by humans (as opposed to the intravenous (IV) lines used for labour induction). Intranasal administration allows for simple, non-invasive treatment that circumvents the issues with the blood brain barrier and is easily used both in humans and in mice (Neumann et al. (2013)). Recent literature suggests this is a promising mode of administration for oxytocin to enter the brain (Galbusera et al. (2017); Pagani et al. (2020))

Importantly, given the substantial heterogeneity of ASD, there is a need for studies to delineate phenotype-based subsets that may respond to oxytocin treatment (Ecker and Murphy (2014); Guastella and Hickie (2016)). This is perhaps best demonstrated by Engelman and colleagues (2008) in their co-clinical study of lung cancer (Engelman et al. (2008)). A clinical trial of a promising therapeutic failed to show treatment effect in their population. They simultaneously treated three different genetic knockout mouse strains, with the same treatment used in humans. The group realized that two of the strains responded $100 \%$ to the treatment, while one did not. Armed with this genetic information, they divided the clinical population into subsets by genotype and found that, in fact, all the patients not carrying the genetic mutation of the non-responder mouse model improved with the treatment. To this end, a study is necessary that incorporates numerous phenotypes across multiple mouse lines, and also makes use of multivariate analyses to inform clinical trials, all in the context of ASD.

Numerous studies have spoken to the utility of magnetic resonance imaging (MRI) in the stratification of ASD individuals into biologically homogeneous subgroups (Bernhardt et al. (2016); Ecker and Murphy (2014); Hong et al. (2018); Hrdlicka et al. (2005); Kushki et al. (2019)). Magnetic resonance imaging (MRI) 
offers the ability to quantify the structural phenotype of both mice and humans, allowing for whole brain coverage and translatability to human imaging studies, both in acquisition and analysis (Chen and Nieman (2011); Hong et al. (2018); Lerch et al. (2011); Nieman et al. (2018); Szulc et al. (2015)). It also affords the additional advantages of high-throughput, having a link with behavior (Anacker et al. (2016); Ellegood et al. (2015, 2013); Lerch et al. (2011); Nieman et al. (2007)), showing evidence of plasticity with exposure (Vousden (2018); Zhang et al. (2018)), and having sensitivity to the neurological effects of interventions like drugs (Bade et al. (2017); Dudek et al. (2015, 2016); Lu et al. (2007); Perrine et al. (2015); Scholz et al. (2015); van der Plas et al. (2020); Vousden (2018); Wheeler et al. (2013); Zhang et al. (2018)).

To explore if we could understand patterns of response in mice, we executed a mouse study in parallel, akin to a co-clinical trial. Specifically, a large randomized, double-blind, placebo-controlled, preclinical study on chronic intranasal oxytocin treatment in three different mouse models related to autism was performed. A wide range of behavioral and neuroanatomical phenotypes were assessed, in a highthroughput method of treatment evaluation.

\section{Methods}

\subsection{Subjects}

Three in-bred strains of autism mouse models were used: the 16p11.2 heterozygous knockout (B6129S-Del(7Slx1b-Sept1)4Aam/J; JAX \#013128)(Horev et al. (2011))(henceforth referred to as "16p"), the Fmr1 hemizygous knockout (FVB.129P2-Pde6b+ Tyrc-ch Fmr1tm1Cgr/J; JAX \#004624)(Bakker et al. (1994))(henceforth referred to as "Fmr1"), and the Shank3 exon 4-9 (ANK domain) homozygous knockout (B6(Cg)-Shank3tm1.2Bux/J; JAX \#017890)(Bozdagi et al. (2010))(henceforth referred to as "Shank3"). The mice were on the following background strains, respectively: B6129SF1/J (JAX \#101043)(henceforth referred to as "129"), FVB.129P2Pde6b + Tyrc-ch/AntJ (JAX \#004828)(henceforth referred to as "FVB"), C57BL/6J (JAX \#000664)(henceforth referred to as "C57").

These strains were chosen because they were genetic models with high face validity. Specifically, they are models with strong analogies to the human condition. For example, the Fmr1 mouse line is a well studied model of the most common single gene mutation related to autism. More pragmatic considerations like availability were also considered, along with the models' distributions in the clusters from Ellegood et al. (2015).

Active colonies for each strain were maintained at The Centre for Phenogenomics (TCP). Breeders were set up to yield control litter-mates for each strain. Specifically, for the $16 p$ strain, heterozygous mice were bred with wildtype 129 mice to yield the desired heterozygous mutants and wildtype control litter-mates. For the Fmr1 strain, heterozygous females were bred with wildtype males to yield hemizygous males and wildtype control litter-mates. For the Shank3 mice, two heterozygous mice were bred to yield homozygous Shank3 mutants and wildtype control littermates.

Mice were group housed, and an attempt was made to achieve a sample size of 14 male mice per genotype, per strain, per treatment (Table 1). The sample size 
(a) Totals- Behavior

\begin{tabular}{c|c|c|c} 
Strain & Total & Oxytocin & Placebo \\
\hline $16 p$ & 30 & 15 & 15 \\
129 & 29 & 15 & 14 \\
Fmr1 & 29 & 14 & 15 \\
FVB & 30 & 13 & 16 \\
Shank3 & 36 & 17 & 19 \\
C57 & 26 & 12 & 14
\end{tabular}

(b) Totals- Sociability

\begin{tabular}{c|c|c|c} 
Strain & Total & Oxytocin & Placebo \\
\hline $16 p$ & 14 & 9 & 5 \\
129 & 17 & 10 & 7 \\
Fmr1 & 18 & 8 & 10 \\
FVB & 18 & 10 & 8 \\
Shank3 & 29 & 13 & 16 \\
C57 & 19 & 10 & 9
\end{tabular}

Table 1: Tables depicting the sample size in each strain, broken down by treatment. A minimum of $\mathrm{n}=14$ was aimed for per genotype, per strain, per treatment. Table (a) shows the samples for all behaviors except sociability. Table (b) shows the reduced sample size due to failed acquisition in the sociability tri-chamber test.

Totals- Imaging

\begin{tabular}{|c|c|c|c|c|c|c|c|c|}
\cline { 2 - 8 } \multicolumn{1}{c|}{ Timepoint } & \multicolumn{2}{c|}{5 wks } & \multicolumn{2}{c|}{ 8wks } & \multicolumn{2}{c|}{ 9wks } & \multicolumn{2}{c|}{ Ex vivo } \\
\hline Strain & Oxy & Pl & Oxy & Pl & Oxy & Pl & Oxy & Pl \\
\hline $16 p$ & 6 & 6 & 6 & 9 & 10 & 10 & 15 & 15 \\
129 & 3 & 9 & 7 & 8 & 9 & 12 & 14 & 15 \\
Fmr1 & 10 & 8 & 11 & 9 & 11 & 7 & 15 & 14 \\
FVB & 14 & 14 & 14 & 12 & 12 & 10 & 16 & 13 \\
Shank3 & 19 & 16 & 19 & 16 & 18 & 12 & 19 & 17 \\
C57 & 13 & 11 & 14 & 12 & 12 & 12 & 14 & 12 \\
\hline
\end{tabular}

Table 2: Table depicting the number of images that passed quality control at each imaging time point in each strain, broken down by treatment. A minimum of $n=14$ was aimed for per genotype, per strain, per treatment. Although all mice were scanned at all time points, some images were excluded due to motion artifacts or low SNR.

was chosen based off a power analysis conducted a priori that determined that 14 subjects in each group should be sufficient to detect group differences, based off the variability in the chosen behavioral and neuroanatomical phenotypes. Data was collected and analyzed for all mice for all behavioral tests, except for sociability. Although the software appeared to be recording, the authors later discovered that one of the laptops failed to acquire the sociability data, leading to a loss of approximately $40 \%$ of the social behavior data (reduced sample sizes are displayed in Table 1b).

All studies and procedures were approved by the TCP Animal Care Committee, in accordance with recommendations of the Canadian Council on Animal Care, the requirements under the Animals for Research Act, RSO1980, and the TCP Committee Policies and Guidelines. Mice were maintained under controlled conditions (25 C, 12 hour cycle) at TCP in sterile, individually ventilated cages and were provided standard chow (Harlan, Teklad Global) and sterile water ad libitum via an automated watering system. 


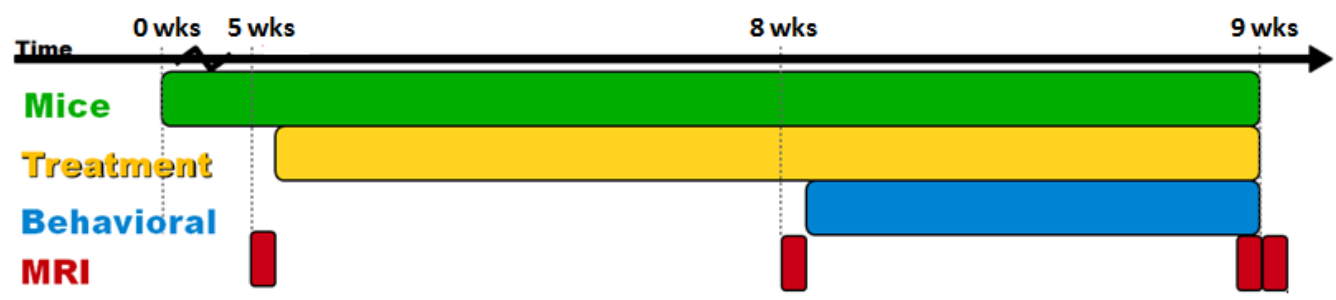

Figure 1: Time-line illustrating the project design. Green indicates the life of the mice, yellow indicates treatment administration, blue indicates period of behavioral testing, while red indicates occurrences of magnetic resonance imaging (MRI).

\subsection{Experimental Time-line}

The experimental time-line is outlined in Figure 1. At five weeks of age, mice underwent in vivo manganese-enhanced magentic resonance imaging (MEMRI) scanning and were randomly assigned to a treatment group (oxytocin or placebo) such that the experimenter remained blinded. Mice were treated everyday, for 28 days total. After an in vivo MEMRI scan at postnatal week 8, mice were assessed on four different behavioral paradigms, while still receiving treatment. At nine weeks of age, the mice were scanned with in vivo MEMRI once more, perfused, and scanned ex vivo at a later time-point. The study was designed to be an exploratory study and therefore no primary outcome was defined before the study started.

The protocol was designed to maximize throughput, and therefore the behaviors chosen were quick to perform, with little intervention or lasting (Crawley (2007)). The behavioral tests were conducted in proximity to each other to minimize the variability between the brain and behavioral phenotypes (PAYLOR et al. (2006)). Similarly, the age of the mice was chosen so that single day variations would not have large effects on brain or behavioral phenotypes. The length of treatment was chosen to probe chronic treatment effects, while remaining manageable for highthroughput. To increase replicability, the ex vivo scan was performed to parallel the protocol from Ellegood et al. (2015). Great care was taken in the conception of this project to ensure that effects observed would be due to treatment and not confounding effects. Pilot testing involving wildtype mice was employed to ensure expected behavioral results before the main study commenced.

Although it is typical to space behavioral tests apart by several days, the methods employed were developed to increase throughput to maximize the number of subjects in the study, thereby increasing the statistical power to detect a treatment effect (Crawley (2007); PAYLOR et al. (2006)). Data from this study was compared to the literature as well as previous data acquired from the lab to ensure that the distribution of the data was expected. Specifically, if an effect of methodology was present, the distribution of the data from later behavioral tests (i.e. Open Field) would skew from the expected distribution based off previous literature (where the test was employed alone or spaced apart from other tests). Expected differences due to genotype (i.e. placebo-treated $16 p$ vs placebo-treated 129 control) would also be altered if an effect of protocol was present. Other measures were additionally implemented to ensure minimal interference; for example, the order the behavioral tests were performed was chosen based off studies investigating effects of training history (Crawley (2007); McIlwain et al. (2001)). 


\subsection{Oxytocin Treatment}

Oxytocin (Sigma-Aldrich) was dissolved in saline and administered intranasally everyday for 28 days. Each morning, between 10am and 11am, the mice received $0.15 \mu \mathrm{g} / 10 \mu \mathrm{L}$. This dose was chosen to be $0.6 \mathrm{IU}$, too low to produce peripheral effects and similar to the quantity used in humans (Bales et al. (2013); Meziane et al. (2015); Neumann et al. (2013)). Control mice received the same quantity of saline (placebo). A similar protocol was used as Huang et al (2014) (Huang et al. (2014)): a 200-ul Eppendorf pipette was used for administration, and drops of the solution were gently placed equally on both nostrils of each mouse. The primary experimenter was blinded to treatment and genotype, and was only unblinded at the time of analysis, when experiments were over.

\subsection{Behavioral Phenotype}

On the third week of treatment, the mice were assessed for repetitive behaviors (as assessed by grooming), social behaviors (three chamber sociability task), anxiety and hyperactivity (open field), learning and motor coordination (rotarod), and memory (novel object recognition).

\subsubsection{Statistics}

Behavioral data was analyzed using the $\mathrm{R}$ statistical language ( $\mathrm{R}$ Core Team, 2016)(R Core Team (2017)). The data was assessed in two ways, to look at a general treatment effect across genotypes and background strains, as well as within strain.

In the former, a linear mixed effects model was used, because they incorporate both fixed and random effects and are useful for longitudinal data, as well as unbalanced study designs (Bates et al. (2015); Pinheiro and Bates (2000))(see (Vousden et al. (2018)) and (Qiu et al. (2018))for fuller explanations on similar data). In this case, linear mixed effects models were created and compared using log-likelihood tests to determine the effect of genotype (defined as wildtype, $16 p$, Fmr1, or Shank3) and treatment, and their interaction on each behavioral test (see Equation 1). Random intercepts for each background strain were incorporated.

$$
\begin{array}{r}
y_{i j}=\beta_{0}+\beta_{1} \text { Genotype }+\beta_{2} \text { Treatment }+\beta_{3} \text { Genotype:Treatment }+b_{i} \text { Strain }_{i}+\epsilon_{i j} \\
\text { where Genotype is defined as wildtype, 16p, Fmr1, or Shank3, } \\
\text { and Strain is defined as 129, FVB, or C57, }
\end{array}
$$

and $y_{i j}$ is the $j^{\text {th }}$ measurement of the dependent variable for strain $i$.

Additional information regarding treatment response and genotype effect was assessed by subsetting by background strain (129, FVB, C57) and using traditional linear regression analysis (see Equation 2). For each strain, separate linear models were created and compared using ANOVA, to determine whether a particular fixed effect (treatment, genotype, or their interaction) significantly improved the model. The distribution within strain of each behavioral test was also assessed and corrected for, before analysis. The genotype effect was used to compare to existing behavioral literature. All data was corrected for multiple comparisons using false discovery rate (FDR) correction (Genovese et al. (2002)), with q-values pooled by treatment, genotype, and interaction independently. 


$$
\begin{array}{r}
y_{i}=\beta_{0}+\beta_{1} \text { Genotype }+\beta_{2} \text { Treatment }+\beta_{3} \text { Genotype:Treatment }+\epsilon_{i} \\
\text { where Genotype is defined as wildtype or mutant, } \\
\text { and one model was created for each of the background strains, } \\
\text { and } y_{i} \text { is the measurement of the dependent variable for mouse } i .
\end{array}
$$

To explore the multivariate nature of the project, principle component analysis (PCA) was employed. Due to the reduced sample size in the sociability data, analyses were done on two sets of the data: 1) all mice that had grooming, open field, and rotarod data ("all mice, no sociability data")(see Table 1a), and 2) the subset of mice that had grooming, open field, rotarod, and sociability data ("subset of mice that have sociability data")(see Table 1b).

\subsubsection{Behavioral Tests}

A description of each of the behavioral tests follows (Crawley (2007); Silverman et al. (2010)), in the order they were performed:

Sociability The three-chambered sociability apparatus consists of a rectangular box with three chambers, with a wire cup placed in either side chamber. The mouse is habituated for 10 minutes during which it can access all three chambers. After this time, a novel stranger mouse is placed under a wire-cup in one of the side chambers. The mouse is observed for an additional 10 minutes during which measures such as time (s) spent in each of the three chambers, specifically near/sniffing the wire cups (near the novel mouse) are observed using an overhead video system, manually scored, and then compared. Mice that are not considered social spend either an equivalent amount of time between the two cups or show a preference for the empty cup (away from the novel mouse).

Rotarod The rotarod test was run on a system (Rota-rod/RS, Panlab, Harvard Apparatus) with the capacity to run up to five mice at a time (though no more than three were ever run). For the rotarod test, mice go through two types of trials, pretrials and test-trials, over two days. Pre-trials are sessions where the mice are allowed to learn how to stay on the rod for $10 \mathrm{~s}$, when it is only rotating at 4 revolutions per minute (rpm). The number of attempts it takes before the mouse stays on the rod for the entire duration is recorded. Latency to fall off the rod is the primary measure of the rotarod test. The mice are given three trials of a total possible five minutes for each trial. The rod starts off at $4 \mathrm{rpm}$ and slowly accelerates over the course of 5 minutes. The latency (s) to fall off the rod is recorded, averaged, and compared. Mice that either have a learning and memory deficit or a motor deficit, perform worse on one or both measures when compared to wildtype controls.

Grooming For the grooming test, the mice are placed into an empty standard cage (Green Line IVC Sealsafe PLUS Mouse, Techniplast) for ten minutes (habituation). The following ten minutes, mice are placed into a different, empty, standard cage and observed for grooming behaviors. Primary measures are duration of grooming bouts ( $\mathrm{s}$ ) as well as number of grooming bouts. Mice with a repetitive behavior 
phenotype spend significantly more time grooming, with more bouts of grooming, than wildtype controls.

Open Field The open field test consists of 10 minutes of testing, where the mouse is placed in an empty box $\left(\right.$ area $=44 \mathrm{~cm}^{2}$ ) and allowed to roam free for the duration of the test. The mouse's motion is recorded by a system (Activity Monitor 7, Med Associates Inc, Fairfax VT) and primary measures investigated are time (s) spent in the center (decreased anxiety) and total distance $(\mathrm{cm})$ moved (hyperactivity).

It should be noted that mice underwent a fifth behavioral test during the study (after the other behavioral tests), the novel object recognition test. This data was removed from the analysis in it's entirety once it was discovered that the tracking software was not accurately capturing the mouse's behavior.

\subsection{Neuroanatomical Phenotype}

Mice were injected in their intraperitoneal (I.P.) cavity with a manganese (Mn) contrast agent $(0.4 \mathrm{mmol} / \mathrm{kg}$ dose of $30 \mathrm{mM} \mathrm{MnCl} 2$ solution) up to 24 hours before the scan (Wadghiri et al. (2004)). A multi-channel 7.0T magnet (Agilent Technologies) was used that allows up to 7 animals to be scanned simultaneously. The mice were anesthetized using 1\% isoflourane during T1-weighted scanning with $90 \mathrm{um}$ isotropic resolution ( $\mathrm{TR}=29 \mathrm{~ms}, \mathrm{TE}=5.37 \mathrm{~ms}, 1$ hour 52 minute scan time). The animals' breathing and temperature were monitored. Mice were imaged at 5, 8, and 9 weeks of age.

One ex vivo MRI scan was performed at least a month after the mice were sacrificed (Elizabeth De Guzman et al. (2016)). The procedure followed closely follows the procedure described in Lerch et al. (2011) and Nieman et al. (2018). To prepare the brains for scanning and enhance contrast, a fixation and perfusion procedure was done as previously described in Cahill et al. (2012). The same multichannel 7.0T magnet (Varian Inc, Palo Alto, CA) was used, with the ability to scan up to 16 brains simultaneously. A T2-weighted 3D fast spin echo sequence was used to yield an isotropic resolution of $40 \mathrm{um}$ (cylindrical acquisition, TR=350ms, $\mathrm{TE}=12 \mathrm{~ms}, 14$ hour scan time)(Spencer Noakes et al. (2017)).

Data from both imaging types was analyzed using image registration and deformation based morphometry approaches as described in Lerch et al. (2011). Briefly, images were linearly (6 parameter, then 12 parameter) and nonlinearly registered together. At completion of this registration, all scans were deformed into alignment with each other in an unbiased fashion. These registrations were performed with a combination of MNI autoreg tools (Collins et al. (1994)) and ANTS (advanced normalization tools)(Avants et al. (2008, 2011)). The changes within regions and across the brain can be examined using deformation based morphometry (DBM) and MAGeT (a multi-atlas registration-based segmentation tool)(Chakravarty et al. (2013)). An atlas that segments 159 structures in the adult mouse brain was used for the in vivo image analysis, and the ex vivo analysis has further delineations resulting in a total of 182 distinct regions (Dorr et al. (2008); Qiu et al. (2018); Richards et al. (2011); Steadman et al. (2014); Ullmann et al. (2013)). Segmentations of all brains passed quality control by visual inspection (see Table 2). 


\subsubsection{Statistics}

Data from both imaging methods was analyzed using the $\mathrm{R}$ statistical language (R Core Team (2017)) using linear mixed effects models (Lmer)(Bates et al. (2015); Pinheiro and Bates (2000)). As with the behavioral data, linear mixed effects models were used to determine the effect of genotype (defined as wildtype, 16p, Fmr1, or Shank3) and treatment on the volume for each region of interest (ROI) or voxel (Equation 3). Random intercepts for each background strain were incorporated. A log-likelihood test was performed to assess the significance of treatment and genotype, and their interaction. Data was analyzed as absolute volumes as well as relative volumes by covarying for total brain volume (Mankiw et al. (2017)).

To assess the effect of treatment on time, brain region volume at the 5 weeks in vivo scan point was used to predict, along with genotype and treatment, the latter brain region volumes (Equation 4). For simplicity, relative volumes were calculated as proportion of total brain volume. Additional information about the genotype effects was also analyzed by subsetting by background strain and assessing the main effects of genotype (mutant versus wildtype) and treatment using linear models in the ex vivo dataset (Equation 5). Multiple comparisons in the data from all analyses was corrected for using false discovery rate (FDR) correction (Genovese et al. (2002)), with p-values pooled by treatment, genotype, and interaction independently.

$$
\begin{array}{r}
y_{i j}=\beta_{0}+\beta_{1} \text { Genotype }+\beta_{2} \text { Treatment }+\beta_{3} \text { Genotype:Treatment }+b_{i} \text { Strain }_{i}+\epsilon_{i j} \\
\text { where Genotype is defined as wildtype, 16p, Fmr1, or Shank3, } \\
\text { and Strain is defined as 129, FVB, or C57, }
\end{array}
$$

and $y_{i j}$ is the $j^{\text {th }}$ measurement of the dependent variable for strain $i$.

$$
\begin{array}{r}
\text { LaterVolume }_{i j}=\beta_{0}+\beta_{1} \text { EarlyVolume }+\beta_{2} \text { Genotype }+\beta_{3} \text { Treatment } \\
+\beta_{4} \text { Genotype:Treatment }+b_{i} \text { Strain }_{i}+\epsilon_{i j}
\end{array}
$$

where Genotype is defined as wildtype, 16p, Fmr1, or Shank3, and Strain is defined as 129, FVB, or C57,

and $y_{i j}$ is the $j^{\text {th }}$ measurement of the dependent variable for strain $i$.

$$
\begin{array}{r}
y_{i}=\beta_{0}+\beta_{1} \text { Genotype }+\beta_{2} \text { Treatment }+\beta_{3} \text { Genotype:Treatment }+\epsilon_{i} \\
\text { where Genotype is defined as wildtype or mutant }
\end{array}
$$

and one model was created for each of the background strains,

and $y_{i}$ is the measurement of the dependent variable for mouse $i$. 


\section{Results}

\subsection{Chronic intranasal oxytocin treatment has little to no ef- fect on the behavioral phenotype of autism-related mouse models}

No significant effect of oxytocin treatment was found on social behavior, regardless of strain or genotype when analyzing the sample as a whole (Figure 2A and E). A significant effect of treatment was found when subsetting for the FVB background strain, with treatment normalizing a deficit in the number of bouts of grooming in the Fmr1 mouse model ( $\mathrm{q}=0.012)$ (Figure 2B). No other effects survived correction for multiple comparisons (see Figure $3 \mathrm{~A}$ ).

Without correction for multiple comparisons, when subsetting for background strain, some trends for treatment were observed. Treatment appeared to decrease the amount of time spent in the center of the open field in the $16 p(\mathrm{p}=0.048)$ and the Fmr1 ( $\mathrm{p}=0.086$, non-significant interaction) mice (Figure $2 \mathrm{~F}$ ). Treatment also had an interesting trending effect on the C57 mice (Shank3 control), by decreasing performance on the rotarod pretrials (interaction $\mathrm{p}=0.070$ ) (Figure $2 \mathrm{C}$ ) and increasing hyperactivity in the open field (interaction $\mathrm{p}=0.093$ ), while not having an effect on the Shank3 mutant mice (Figure 2D).

PCA was employed to further elucidate if a treatment effect was present that was not captured in the individual behaviors but would be captured given a multivariate analysis. Two analyses were run on separate subsets, the first on the full data-set excluding social behaviors ("all mice, no sociability data")(see Table 1a), and the second on the subset of mice that had social behaviors tested ("subset of mice that have sociability data")(see Table $1 \mathrm{~b}$ ). The first two components accounted for $52.5 \%$ and $48.2 \%$ of the total variance, respectively, of the two datasets (see Figure 3B,C). Most of the behavioral tests exhibited negative values for principle component 1 (PC1), in both sets. In contrast, the pre-trials measure of rotarod and the average duration of grooming bouts were positive in both sets. No distinct groups of variables were distinguishable, although measures from the same behavioral test did coincide. Overall, no pattern of treatment response was observed. 

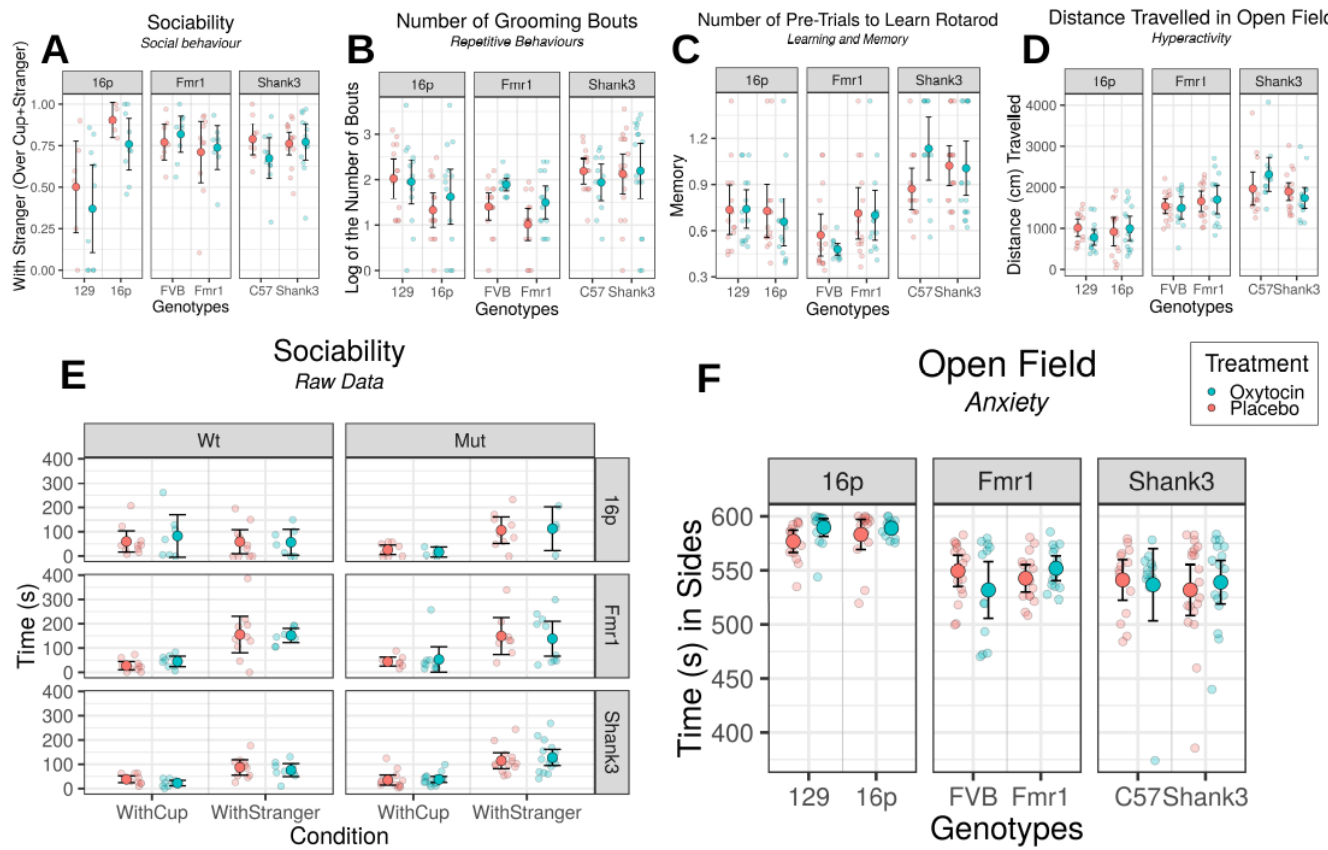

Figure 2: Figures depicting treatment effect in each strain, by genotype. Blue indicates mice treated with oxytocin, red indicates mice treated with saline (placebo). Each point represents one mouse. Bars show mean \pm confidence interval (95\%). Sociability data is shown both as $(\mathbf{E})$ the raw time spent with the mouse and cup, for each mouse by genotype and strain, as well as (A) a ratio of time with stranger over total time with cup and stranger. (B) Number of bouts of grooming in the mice, $(\mathbf{C})$ number of pre-trials required to learn rotarod, (D) distance travelled in the open field, and $(\mathbf{F})$ time spent in the sides $(=$ total - center $)$ of the open field are also shown.

\subsection{Chronic intranasal oxytocin treatment has a trending ef- fect on the neuroanatomy of autism-related mouse mod- els}

Chronic treatment with oxytocin had a weak and focused effect, only changing the volume of the cerebellar peduncle superior and the endopiriform claustrum (intermediate nucleus) regions when assessing relative volumes (see Figures 5 and 6), across all mouselines (using Equation 4). No other brain regions were significant with correction for multiple comparisons, but the pattern of treatment effect, as shown by the voxel-wise analysis, shows alterations in several cerebellar regions, the cingulate cortex, and, interestingly, several regions related to sensory/motor behaviors, like the cuneate nucleus, the dorsal tenia tecta, and the superior olivary complex.

The ex vivo analysis (using Equation 3), showed no significant treatment effect (see Figure 7$)$, only a weak trend $(q=0.195)$ in the Shank3 interaction of cerebellar lobule 9 (white matter). When assessing strain differences (using Equation $5)$, the Shank3 mice showed trending $(q=0.161)$ treatment effect in three regions of the primary somatosensory cortex and the lateral ventricles. As seen in Figure 7 , the genotype differences were significant and widespread, although more so for the $16 p$ and Fmr1 mice, with significant effects in regions such as the midbrain, hippocampus, and cerebellum in the $16 p$ mice, in regions including the hippocampus, cerebellum and white matter tracts in the Fmr1 mice, and in the cerebellar 
peduncle, habenular commissure, and pontine nucleus for the Shank3 mice.

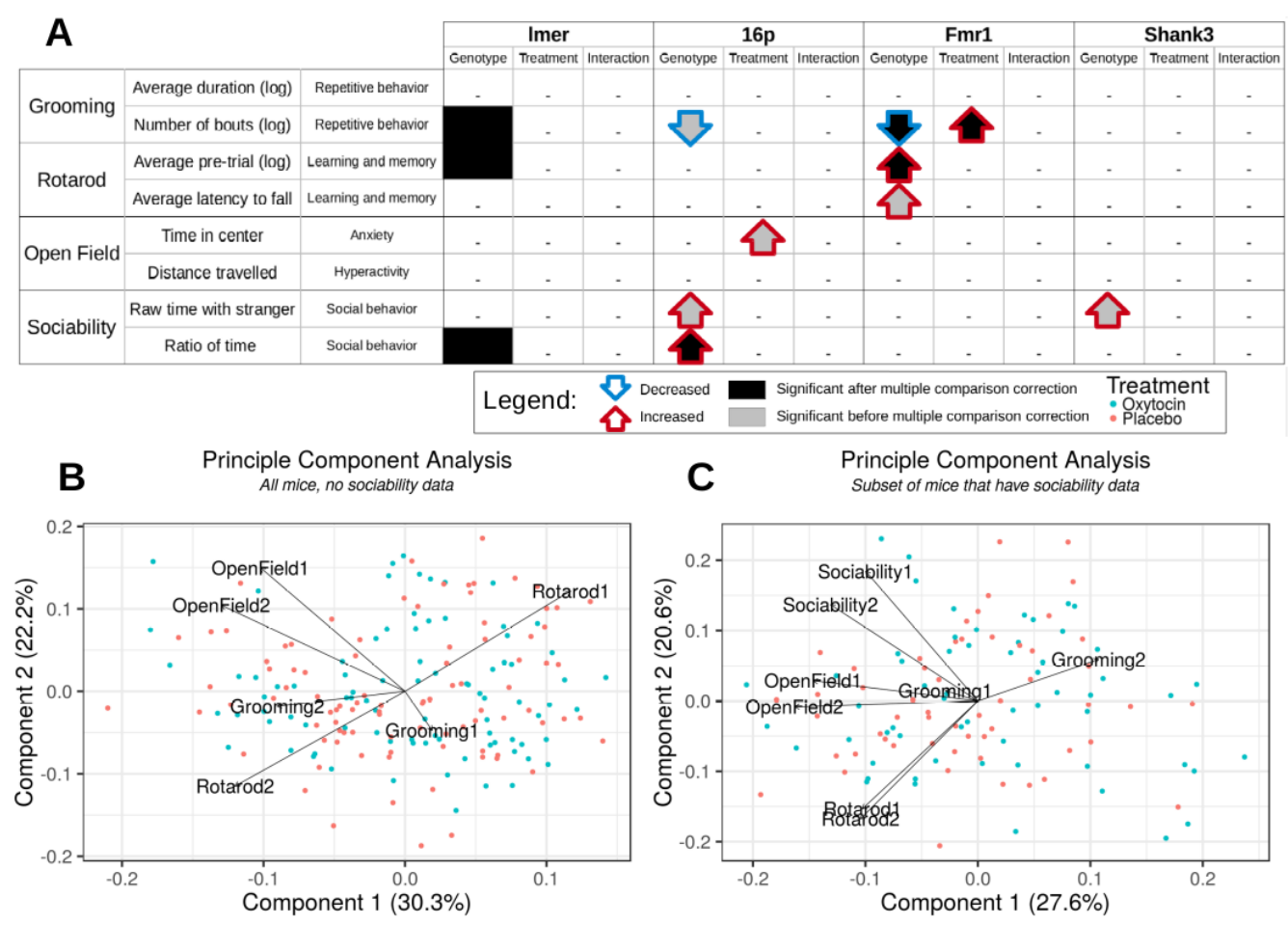

Figure 3: Table $\mathbf{A}$ shows the results of the log-likelihood tests assessing the main effects of treatment and genotype, and their interaction from the linear mixed effects models on the behavioral tests. Each of the behavioral tests are shown, broken down by measure. The table is color-coded to show significant, corrected $\mathrm{q}$ values $(<0.05)$ with a dark background, and trending $(\mathrm{q}<0.10)$ values with a grey background. Arrows indicate changes relative to their respective controls (i.e. $16 p$ mice to 129 mice). Figures $\mathbf{B}$ and $\mathbf{C}$ show the results of the PCA analyses, with the "all mice, no sociability data" set on the left (B) and the "subset of mice that have sociability data" on the right $(\mathbf{C})$. The names of the PCA measures follow down along the table of measures. Specifically, Grooming1 is "average duration" (the first row in the table), Grooming2 is "number of bouts" (second row), Rotarod1 is "average pre-trials" (3rd row), Rotarod2 is "average latency to fall" (4th), OpenField1 is "time in center" (5th), OpenField2 is "distance travelled" (6th), Sociability1 is "raw time with stranger" (7th), and Sociability2 is "ratio of time" (last row). As evident from these tables and figures, little to no treatment effect was observed across the multitude of behavioral phenotypic measures employed in this study.

\section{Discussion and Conclusions}

Chronic treatment with intranasal oxytocin produced subtle behavioral and neuroanatomical effects across three different autism mouse models. No significant effect of treatment was found on social behavior, although a significant effect of treatment was found in the Fmr1 mouse, with treatment normalizing a grooming deficit. No other treatment effect on behavior was observed that survived multiple comparisons correction. No pattern of treatment effect was distinguishable when a multivariate method (PCA) was employed. Treatment effect on the neuroanatomy was modest, and primarily apparent when assessing relative volumes. 


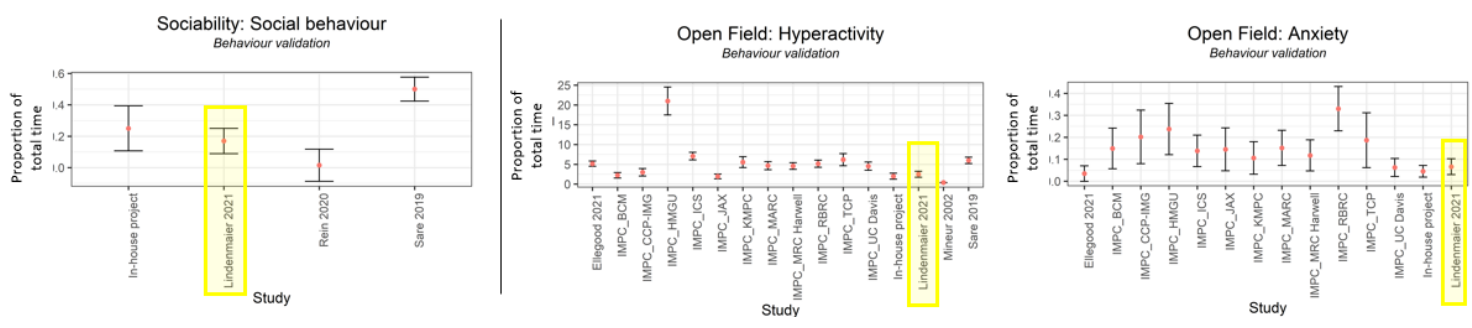

Figure 4: Figures depicting behavioral data from the literature as well as previous studies from within our lab to assess affect of methodology on the behavior of the mice. Mean, standard deviation, and time for the total test were gathered from studies with similar protocols, with preference given to protocols with similar mouse models (Ellegood et al. (2021); Mineur et al. (2002); Rein et al. (2020); Saré et al. (2019)). Data from the International Mouse Phenotypying Consortium (www.mousephenotype.org)(Dickinson et al. (2016)) and as well as from other projects within our lab were added. NB: except where raw data was available, data for these figures was gathered from visual inspection of figures. Figures show proportion of total time spent with the stranger in the three chamber sociability test (a measure of social behavior, left), distance travelled $(\mathrm{cm})$ as a proportion of total time exploring the open field chamber (a measure of hyperactivity, middle), and proportion of total time spent in the center of the open field test (a measure of anxiety, right). Given the distribution of the data from later behavioral tests (i.e. open field) does not skew from the expected distribution based off the literature, it can reasonably be concluded that no effect of methodology was observed.

Although not statistically significant, the pattern of treatment effect in the brain is particularly promising because many are regions that are associated with oxytocin signaling and, moreover, have been implicated in autism pathogenesis. For example, the brain stem and olfactory systems have large populations of oxytocin receptors, and we found (trending) treatment effects in the cuneate nucleus, the superior olivary complex, and the dorsal tenia tecta, among other regions. The superior cerebellar peduncle- a region found to have a trending treatment effect- is a white matter tract that connects the cerebellum to the midbrain. A number of studies have shown aberrations in the structure and function (see Crippa et al. (2016) for review, also Cheng et al. (2010)) of the superior cerebellar peduncle in autism. Moreover, the cerebellum, as a whole, has been implicated in the ethiopathogenesis of autism (for review, see Fatemi et al. (2012), Crippa et al. (2016)). An elegant study in a mouse model of autism demonstrated the important role of the cerebellum in autismrelated behaviors, including the therapeutic potential of cerebellar neuromodulation in autism (Tsai et al. (2012)). The endopiriform claustrum, another region that was 
bioRxiv preprint doi: https://doi.org/10.1101/2021.01.13.426562; this version posted August 6, 2021. The copyright holder for this preprint (which was not certified by peer review) is the author/funder, who has granted bioRxiv a license to display the preprint in perpetuity. It is made available under aCC-BY-ND 4.0 International license.

\section{Cerebellar peduncle superior \\ A Absolute volumes over time}

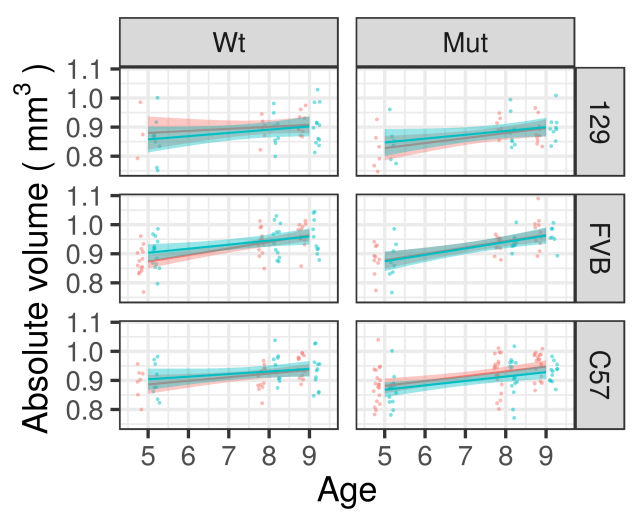

\section{B}

\section{Endopiriform claustrum (I.N.)}

Absolute volumes over time

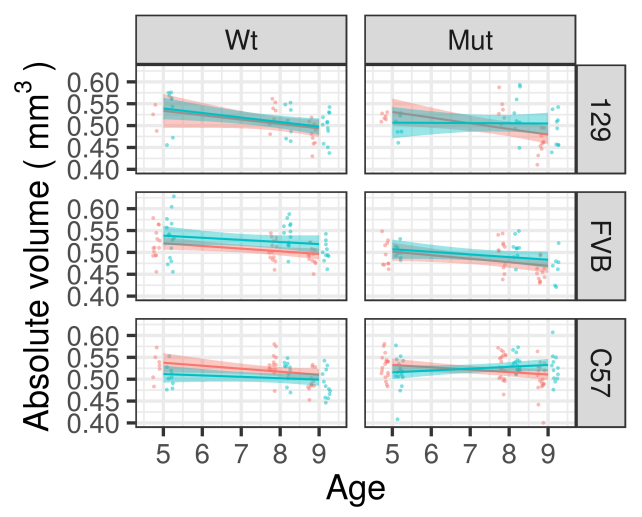

\section{Overall brain volumes \\ C Absolute volumes over time}

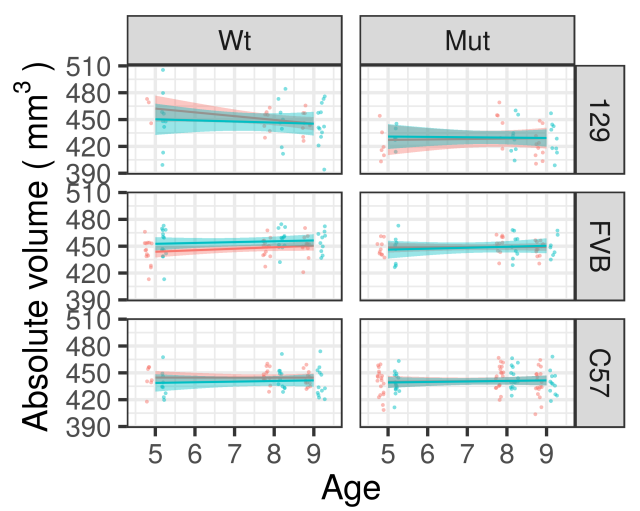

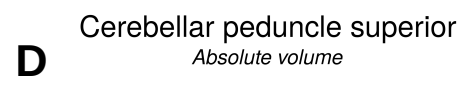
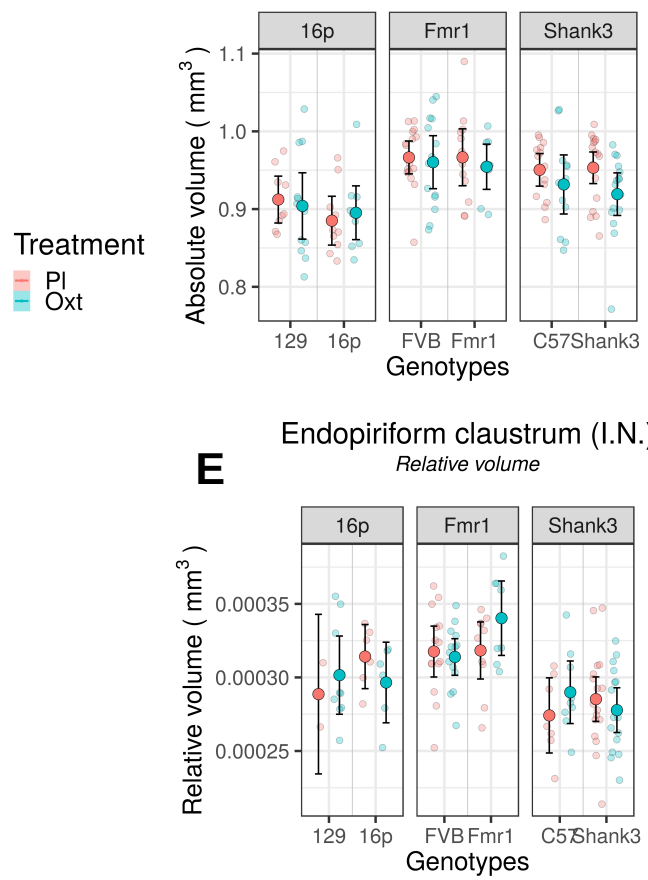

Treatment
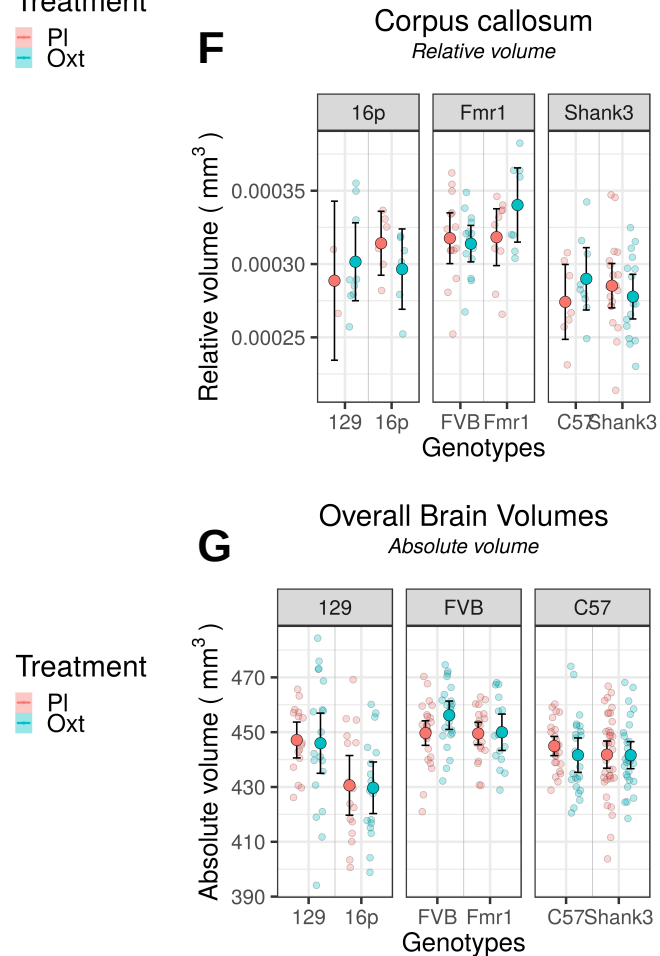

Figure 5: Figures depicting treatment effects of selected regions from in vivo imaging. Figures $\mathbf{A}$ through $\mathbf{C}$ show the change in volume over time of the cerebellar peduncle superior, the endopiriform claustrum, and the total brain volumes. Figures $\mathbf{D}$ through $\mathbf{G}$ show a cross-sectional view of the brain region volumes after 3-4 weeks of treatment, faceted by strain. To better see the treatment effect, two of the figures ( $\mathbf{E}$ and $\mathbf{F}$ ) show relative volume of the regions. With correction for multiple comparisons, no significant treatment effect was seen on any region, though the cerebellar peduncle superior and endopiriform claustrum (intermediate nucleus) showed trending ( $\mathrm{q}=0.155)$ effects (see 6). There were significant genotype differences across brain regions, and overall brain volume. 
found to have a trending treatment effect, is a part of the basal ganglia, the system known to regulate repetitive behaviors. Although the exact function of the claustrum is unknown, it is hypothesized that it plays a role in multisensory integration and is an important relay nucleus to the cortex (Mathur (2014)). Furthermore, a number of regions in the Shank3 mouse model found to be affected by treatment, are related to sensation/perception. There is a wealth of literature on the dysfunction of sensation/perception in autism (see Robertson and Baron-Cohen (2017) for review). Overall, oxytocin's effects on these regions- although modest- are promising for the treatment of autism.

To compare to existing literature, the effect of genotype of the three mutant mice was separately analyzed (see Equations 2 and 5). Without correction for multiple comparisons, all three mutant mice, for the most part, showed behavioral and neuroanatomical differences that were expected based off previous literature (Bernardet and Crusio (2006); Bozdagi et al. (2010); Ellegood et al. (2015); Harony-Nicolas et al. (2017); Horev et al. (2011); Yang et al. (2012)). With multiple comparison correction, this study moderately recapitulated existing literature. Additional analysis comparing to data distributions from previous literature and previous studies within our lab was conducted after the primary results were analyzed, to demonstrate the lack of effect of methodology on the behavior of the mice (see Figure 4).

There are many possible reasons this study did not see a significant effect of treatment on behavior. Although many studies have investigated the promising effects of oxytocin in autism and related models, the majority of those studies investigated the acute effects of treatment (Guastella and Hickie (2016)). One study in rodents found opposing results for acute vs chronic oxytocin administration (Huang et al. (2014)), while another specifically focusing on the social effects of oxytocin, found that chronic administration actually hinders some social behaviors in prairie voles (Bales et al. (2014)). Furthermore, a study of chronic oxytocin treatment in autism patients only found improvements on one secondary measure (Anagnostou et al. (2012)) and another study in youths found no benefit of chronic oxytocin across all social cognition, caregiver, and clinician assessments (Guastella et al. (2015)). As Huang et al. (2014) put it, there seems to be a "translational hurdle" in the movement of oxytocin from acute studies to chronic.

Some studies investigating this translational hurdle have found value in the glutamatergic system, the genetic background of the oxytocin receptor, and in the dosage. A recent study comparing acute and chronic treatment in both mice and humans suggests a unique sensitivity of the glutamatergic system to repeated oxytocin administration may explain the differential behavioral effects of oxytocin between the two lengths of administration (Benner et al. (2021)). Another study that did not find improvements with oxytocin effect in the larger study population, did find significant effects in a subgroup of participants. Their results suggest that efficacy of long-term oxytocin administration in young men with high-functioning ASD depends on the oxytocin dosage and the genetic background of the oxytocin receptor (Kosaka et al. (2016)). Yet another study found a time-course change of efficacy of oxytocin on social behaviors in adults with autism (Owada et al. (2019)), indicating the dose used in this study may be too low or too high, for too long of a period of time. Further studies on these factors may lead to a better understanding of the best protocol to see a significant treatment effect of oxytocin. 
bioRxiv preprint doi: https://doi.org/10.1101/2021.01.13.426562; this version posted August 6, 2021. The copyright holder for this preprint (which was not certified by peer review) is the author/funder, who has granted bioRxiv a license to display the preprint in perpetuity. It is made available under aCC-BY-ND 4.0 International license.

\begin{tabular}{|l|c|c|c|c|c|c|}
\cline { 2 - 7 } \multicolumn{1}{c|}{ A } & \multicolumn{5}{|c|}{ In vivo } \\
\cline { 2 - 7 } & \multicolumn{3}{|c|}{ Absolute } & \multicolumn{3}{c|}{ Relative } \\
\cline { 2 - 7 } & Treatment & Genotype & Interaction & Treatment & Genotype & Interaction \\
\hline Cerebellar peduncle superior & 0.743 & 0.945 & 0.999 & 0.155 & 0.935 & 0.970 \\
\hline Endopiriform claustrum (I.N.) & 0.743 & 0.029 & 0.999 & 0.155 & 0.001 & 0.919 \\
\hline
\end{tabular}

\section{B}

\section{Across strains Interaction treatment effect (20\% FDR) across genotypes (10\% FDR)}
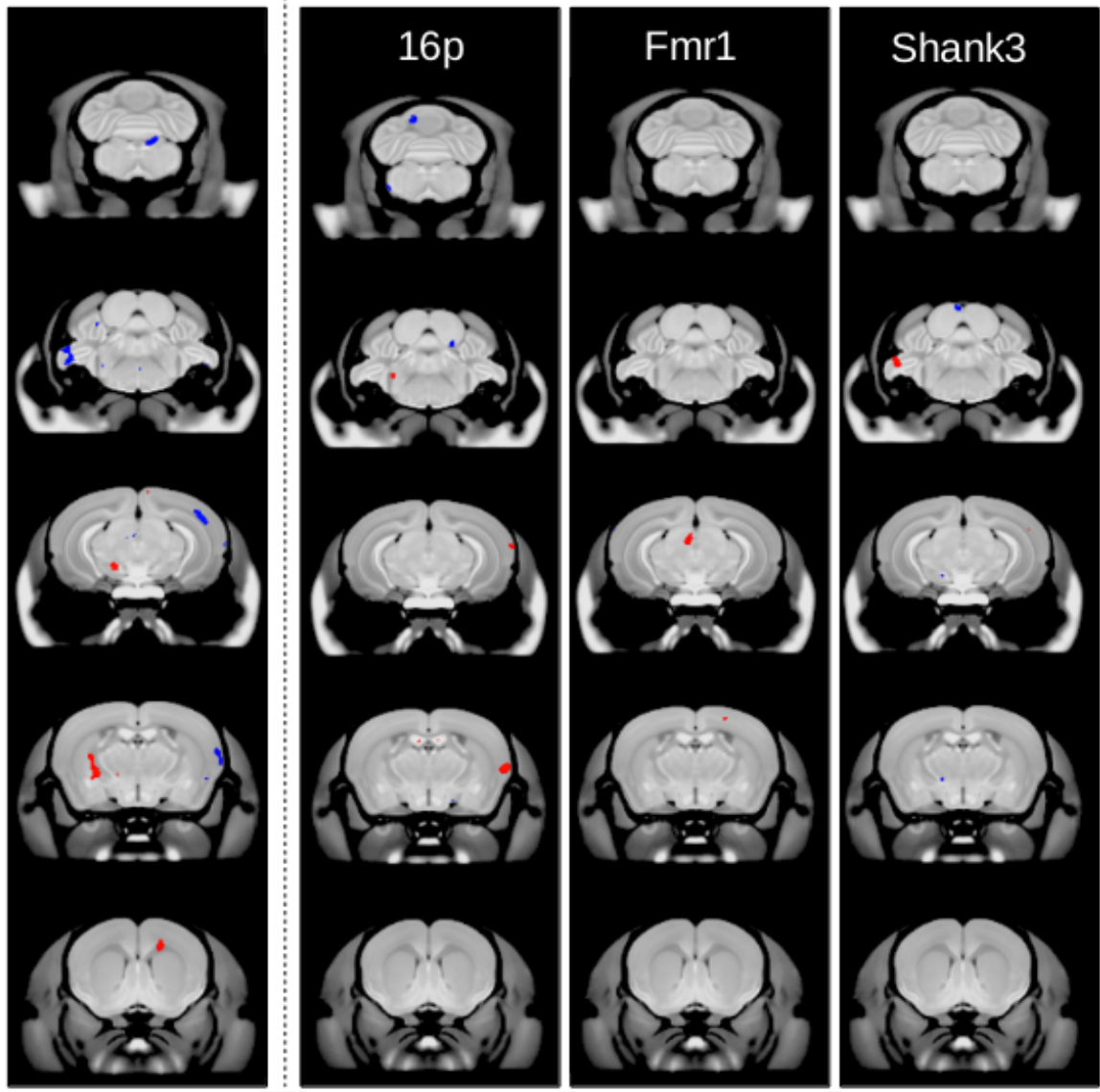

\section{Smaller}

FDR $<0.10$

Larger

Figure 6: Treatment effect in the in vivo data. Top (a) shows the results of the volume-wise linear mixed effects model with main effects of treatment and genotype, with a random intercept for each background strain (using Equation 4). FDR-corrected values are shown with black background indicating significance $(q<10 \%)$ and grey background showing trends. Results from both absolute and relative volume analyses are shown; in this case, relative volumes of each region were calculated as proportion of the total brain volume. The cerebellar peduncle superior and the endopiriform claustrum (I.N. = intermediate nucleus) showed subtle treatment effects. Bottom (b) shows the voxel-wise data analysis, using the linear mixed effects model shown in Equation 3. Colors indicate voxels that were $\mathrm{q}<10 \%$ significant, with red indicating regions that were larger than the reference group and blue indicating smaller. In the case of the treatment effect across strains (left), colours indicate $\mathrm{q}<20 \%$, to better distinguish patterns. These figures clearly depict the subtle effect of treatment response on neuroanatomy. 
Another possible issue for the lack of treatment effect may be due to the study population. We chose to limit the study to older (adolescent/adult) mice to minimize variability and increase our power. However, it is possible that a younger population is needed to see the effects of oxytocin. For example, the association of the plasma oxytocin levels in autism (that was mentioned earlier as a promising reason we expect response to oxytocin) was found in children, and perhaps does not extend to adults (Modahl et al. (1998)). Similarly, one of the only clinical trials that saw improvements with chronic oxytocin treatment was conducted in children (Yatawara et al. (2016)). Developmental processes occur during childhood that could impact the effect of treatment response (Bhardwaj et al. (2006); Pascual-Leone et al. (2011); Sorrells et al. (2018)).

Along these lines, the three mouse lines employed were primarily chosen for their high face validity to autism, and not necessarily their utility for treatment with oxytocin. Specifically, without an underlying deficit in a particular behavior, no effect of oxytocin is expected, regardless of promise. For example, of the three mouse models chosen, only the Fmr1 mouse line is expected to have social deficits, while the literature for the Shank3 model is mixed, and the $16 p$ model does not show deficits. The range of expectations in the behaviours of these mice contributed to our decision to use them, but the lack of social deficits in all three mouse lines found in this study obscures the possible treatment effect of oxytocin on social behavior.

Moreover, some limitations arose during this study. For example, the timeline was designed to maximize throughput and therefore some potentially insightful behavioral tests were omitted. Given the number of brain regions involved in sensation/perception that showed changes due to treatment, a test that specifically evaluated those behaviors may have seen a significant effect of treatment. The reduced sample size (Table 1) for the sociability test (due to failed acquisition) could have also contributed to the lack of treatment effect, due to low power.

Furthermore, there is no current robust method to assess the quantity of oxytocin that is delivered to the brain using the intranasal method. When the treatment was first started, all the mice fought the scruff hold and intranasal administration equally. Near the end of the treatment period, however, approximately half the mice would fight the treatment while the other half remained stationary. The authors assume the mice that ceased avoiding the intranasal application were the ones to receive oxytocin and, through classical conditioning, had learned that the application would quickly lead to pleasant sensations (Benarroch (2013)). Though this was primarily observational, a small sample of mice $(n=14)$ were assessed to see if treatment arm (placebo vs. oxytocin) could be determined just through interaction during treatment after 3 weeks of treatment. With the help of a colleague, the correct treatment arm was confirmed for all the mice in the sample. Although not specific to the brain, this confirms that the intranasal application method was successful in administering oxytocin into the mice.

Along these lines, it is important to consider the dosage employed in this study. Although chosen to be relevant to the clinic, it is on the upper end of doses used in previous studies (Bales et al. (2013); Guastella and Hickie (2016); Neumann et al. (2013); Quintana et al. (2019)). Recent literature suggests an inverted U-curve doseresponse relationship of oxytocin, and therefore the promise of oxytocin treatment can not be dismissed given the single dose investigated in this study (Owada et al. (2019)). Similarly, previous studies suggest a potential deterioration of efficacy of 
chronic treatment, indicating that perhaps the treatment period in this study was too long to detect effects of oxytocin (Benner et al. (2021); Owada et al. (2019)).

It remains possible that the treatment effects that were observed were solely due to peripheral treatment effects. Leng and Ludwig (2016) argue that it is unlikely that any intranasal method has successfully delivered oxytocin to the brain and the effects that are seen, for example in Neumann et al. (2013), are due to the oxytocin signaling system responding to peripheral changes in oxytocin levels. Although a
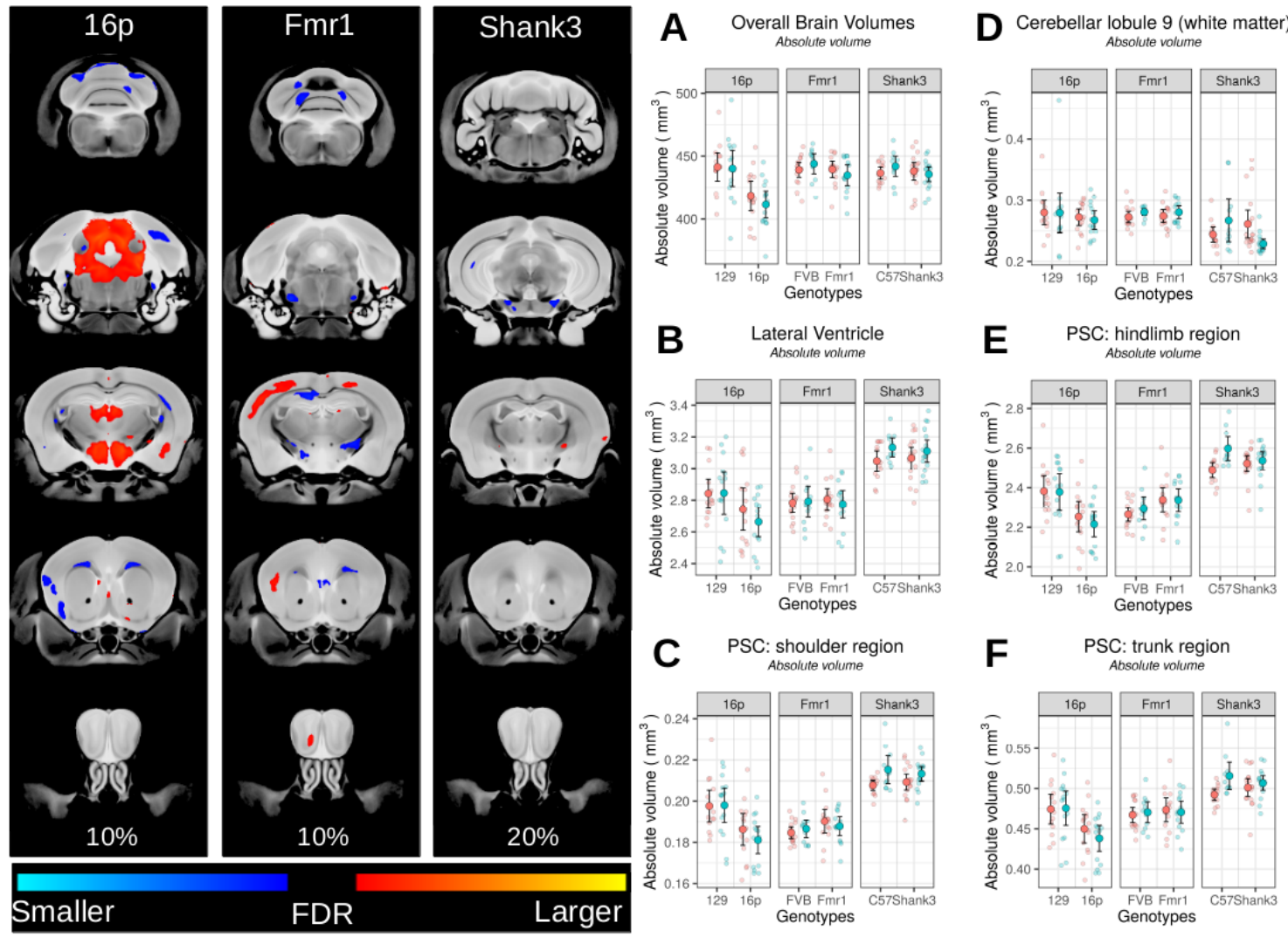

Figure 7: Figures depicting the results of the ex vivo analyses. On the left, genotype effects are shown from the subsetted (by background strain) voxelwise analyses (Equation 5). On the right, the graphs depict treatment effect across strains for six regions, including overall brain volumes. $\mathrm{PSC}=$ Primary Somatosensory Cortex

contested hypothesis (Galbusera et al. (2017); Pagani et al. (2020)), more tests that assess the utility of intranasal oxytocin, like proper dose-response studies, with peripheral effects controlled for (Leng and Ludwig (2016)), are necessary.

Future studies should aim to explore other behavioral tests, population sets, and administration methods. The authors recognize that the exclusion of female mice from this study contributes to the ongoing sex bias in neuroscience and this study should be replicated in female mice to truly assess the utility of oxytocin administration in autism mouse models.

The possibility remains that the three autism mouse models employed in this study- the 16p, Fmr1, and Shank3 mouse models- are non-responders to oxytocin. Despite the limitations, the study is one of few studies to assess the effects of chronic oxytocin treatment on the behavioral and neuroanatomy of multiple mouse models of autism. 


\section{Declarations}

\subsection{Ethics approval and consent to participate}

All studies and procedures were approved by The Centre for Phenogenomics (TCP) Animal Care Committee, in accordance with recommendations of the Canadian Council on Animal Care, the requirements under the Animals for Research Act, RSO1980, and the TCP Committee Policies and Guidelines.

\subsection{Availability of data and material}

The datasets from this study are available from the corresponding author on reasonable request.

\subsection{Competing interests}

The authors declare that they have no competing interests.

\subsection{Funding}

This work was supported by funding from the Brain Canada Foundation, The Azrieli Foundation, Health Canada, Province of Ontario Neurodevelopmental Disorders (POND) Network, and the Ontario Brain Institute (OBI). Z.L. was supported by the developmental neurosciences research training award from the Brain Canada Foundation, Kids Brain Health Network, and the Hospital for Sick Children.

\subsection{Authors' contributions}

Conception and interpretation of this project were done by ZL, JE, EA, and JPL. Design was primarily ZL, JE, JF, EA, and JPL, while acquistion/analysis was primarily ZL, MS, KE. Additionally, ZL, JE, KE, and JPL contributed to the writing or revision of the manuscript, and all authors read and approved the final manuscript

\section{Acknowledgements}

The authors would like to thank Darren Fernandes, Chris Hammill, Dr. Dulcie Vousden, and Matthijs Van Eede for helping with data analysis, Christine Laliliberte, Dr. Dulcie Vousden, and Dr. Jill Silverman for procedural assistance, and Drs. Brad Wouters and Mark Henkelman for advice and guidance.

\section{References}

Anacker, C., Scholz, J., O’Donnell, K. J., Allemang-Grand, R., Diorio, J., Bagot, R. C., Nestler, E. J., Hen, R., Lerch, J. P., and Meaney, M. J. (2016). Neuroanatomic Differences Associated With Stress Susceptibility and Resilience. Biological Psychiatry, 79(10):840-849. 
Anagnostou, E., Soorya, L., Chaplin, W., Bartz, J., Halpern, D., Wasserman, S., Wang, A. T., Pepa, L., Tanel, N., Kushki, A., and others (2012). Intranasal oxytocin versus placebo in the treatment of adults with autism spectrum disorders: a randomized controlled trial. Mol Autism, 3(1):16.

Andari, E., Nishitani, S., Kaundinya, G., Caceres, G. A., Morrier, M. J., Ousley, O., Smith, A. K., Cubells, J. F., and Young, L. J. (2020). Epigenetic modification of the oxytocin receptor gene: implications for autism symptom severity and brain functional connectivity. Neuropsychopharmacology, 45(7):1150-1158.

Andari, E., Richard, N., Leboyer, M., and Sirigu, A. (2016). Adaptive coding of the value of social cues with oxytocin, an fMRI study in autism spectrum disorder. Cortex, 76:79-88.

Aoki, Y., Yahata, N., Watanabe, T., Takano, Y., Kawakubo, Y., Kuwabara, H., Iwashiro, N., Natsubori, T., Inoue, H., Suga, M., Takao, H., Sasaki, H., Gonoi, W., Kunimatsu, A., Kasai, K., and Yamasue, H. (2014). Oxytocin improves behavioural and neural deficits in inferring others' social emotions in autism. Brain, 137(11):3073-3086.

Aoki, Y. and Yamasue, H. (2015). Reply: Does imitation act as an oxytocin nebulizer in autism spectrum disorder? Brain, 138(7):e361-e361.

Avants, B., Epstein, C., Grossman, M., and Gee, J. (2008). Symmetric diffeomorphic image registration with cross-correlation: Evaluating automated labeling of elderly and neurodegenerative brain. Medical Image Analysis, 12(1):26-41.

Avants, B. B., Tustison, N. J., Song, G., Cook, P. A., Klein, A., and Gee, J. C. (2011). A reproducible evaluation of ANTs similarity metric performance in brain image registration. NeuroImage, 54(3):2033-2044.

Bade, A. N., Gendelman, H. E., Boska, M. D., and Liu, Y. (2017). MEMRI is a biomarker defining nicotine-specific neuronal responses in subregions of the rodent brain. Am J Transl Res, 9(2):601-610.

Bakker, C., Verheij, C., and et al. (1994). Fmr1 knockout mice: A model to study fragile X mental retardation. Cell, 78(1):23-33.

Bales, K. L., Perkeybile, A. M., Conley, O. G., Lee, M. H., Guoynes, C. D., Downing, G. M., Yun, C. R., Solomon, M., Jacob, S., and Mendoza, S. P. (2013). Chronic Intranasal Oxytocin Causes Long-Term Impairments in Partner Preference Formation in Male Prairie Voles. Biological Psychiatry, 74(3):180-188.

Bales, K. L., Solomon, M., Jacob, S., Crawley, J. N., Silverman, J. L., Larke, R. H., Sahagun, E., Puhger, K. R., Pride, M. C., and Mendoza, S. P. (2014). Longterm exposure to intranasal oxytocin in a mouse autism model. Translational Psychiatry, 4(11):e480.

Bates, D., Mächler, M., Bolker, B., and Walker, S. (2015). Fitting Linear MixedEffects Models Using lme4. Journal of Statistical Software, 67(1):1-48.

Benarroch, E. E. (2013). Oxytocin and vasopressin: Social neuropeptides with complex neuromodulatory functions. Neurology, 80(16):1521-1528. 
Benner, S., Aoki, Y., Watanabe, T., Endo, N., Abe, O., Kuroda, M., Kuwabara, H., Kawakubo, Y., Takao, H., Kunimatsu, A., Kasai, K., Bito, H., Kakeyama, M., and Yamasue, H. (2021). Neurochemical evidence for differential effects of acute and repeated oxytocin administration. Molecular Psychiatry, 26:710-720.

Bernardet, M. and Crusio, W. E. (2006). Fmr1 KO Mice as a Possible Model of Autistic Features. The Scientific World JOURNAL, 6:1164-1176.

Bernhardt, B. C., Di Martino, A., Valk, S. L., and Wallace, G. L. (2016). Neuroimaging-Based Phenotyping of the Autism Spectrum. In Current Topics in Behavioral Neurosciences, volume 30, pages 341-355. Springer Verlag.

Bhardwaj, R. D., Curtis, M. A., Spalding, K. L., Buchholz, B. A., Fink, D., BjorkEriksson, T., Nordborg, C., Gage, F. H., Druid, H., Eriksson, P. S., and Frisen, J. (2006). Neocortical neurogenesis in humans is restricted to development. Proceedings of the National Academy of Sciences, 103(33):12564-12568.

Bittel, D. C., Kibiryeva, N., Dasouki, M., Knoll, J. H., and Butler, M. G. (2006). A 9-year-old male with a duplication of chromosome 3p25.3p26.2: Clinical report and gene expression analysis. American Journal of Medical Genetics Part A, 140A(6):573-579.

Bozdagi, O., Sakurai, T., Papapetrou, D., Wang, X., Dickstein, D. L., Takahashi, N., Kajiwara, Y., Yang, M., Katz, A. M., Scattoni, M. L., and others (2010). Haploinsufficiency of the autism-associated Shank3 gene leads to deficits in synaptic function, social interaction, and social communication. Mol Autism, 1(1):15-15.

Cahill, L. S., Laliberté, C. L., Ellegood, J., Spring, S., Gleave, J. A., van Eede, M. C., Lerch, J. P., and Henkelman, R. M. (2012). Preparation of fixed mouse brains for MRI. NeuroImage, 60(2):933-939.

Chakravarty, M. M., Steadman, P., Van Eede, M. C., Calcott, R. D., Gu, V., Shaw, P., Raznahan, A., Collins, D. L., and Lerch, J. P. (2013). Performing LabelFusion-Based Segmentation Using Multiple Automatically Generated Templates HHS Public Access. Hum Brain Mapp, 34(10):2635-2654.

Chen, X. J. and Nieman, B. J. (2011). Mouse Phenotyping with MRI. In Schröder, L. and Faber, C., editors, Methods in Molecular Biology, volume 771, pages 595-631. Humana Press, Totowa, NJ.

Cheng, Y., Chou, K.-H., Chen, I.-Y., Fan, Y.-T., Decety, J., and Lin, C.-P. (2010). Atypical development of white matter microstructure in adolescents with autism spectrum disorders. NeuroImage, 50(3):873-882.

Collins, D. L., Neelin, P., Peters, T. M., and Evans, A. C. (1994). Automatic 3D intersubject registration of MR volumetric data in standardized Talairach space. Journal of computer assisted tomography, 18(2):192-205.

Crawley, J. N. (2007). What's wrong with my mouse?: behavioral phenotyping of transgenic and knockout mice. Wiley-Interscience, Hoboken, N.J, 2nd ed edition. 
Crippa, A., Del Vecchio, G., Busti Ceccarelli, S., Nobile, M., Arrigoni, F., and Brambilla, P. (2016). Cortico-Cerebellar Connectivity in Autism Spectrum Disorder: What Do We Know So Far? Frontiers in Psychiatry, 7:20.

de la Torre-Ubieta, L., Won, H., Stein, J. L., and Geschwind, D. H. (2016). Advancing the understanding of autism disease mechanisms through genetics. Nature Medicine, 22(4):345-361.

Dickinson, M. E., Flenniken, A. M., Ji, X., Teboul, L., Wong, M. D., White, J. K., Meehan, T. F., Weninger, W. J., Westerberg, H., Adissu, H., Baker, C. N., Bower, L., Brown, J. M., Caddle, L. B., Chiani, F., Clary, D., Cleak, J., Daly, M. J., Denegre, J. M., Doe, B., Dolan, M. E., Edie, S. M., Fuchs, H., Gailus-Durner, V., Galli, A., Gambadoro, A., Gallegos, J., Guo, S., Horner, N. R., Hsu, C.-W., Johnson, S. J., Kalaga, S., Keith, L. C., Lanoue, L., Lawson, T. N., Lek, M., Mark, M., Marschall, S., Mason, J., McElwee, M. L., Newbigging, S., Nutter, L. M. J., Peterson, K. A., Ramirez-Solis, R., Rowland, D. J., Ryder, E., Samocha, K. E., Seavitt, J. R., Selloum, M., Szoke-Kovacs, Z., Tamura, M., Trainor, A. G., Tudose, I., Wakana, S., Warren, J., Wendling, O., West, D. B., Wong, L., Yoshiki, A., MacArthur, D. G., Tocchini-Valentini, G. P., Gao, X., Flicek, P., Bradley, A., Skarnes, W. C., Justice, M. J., Parkinson, H. E., Moore, M., Wells, S., Braun, R. E., Svenson, K. L., de Angelis, M. H., Herault, Y., Mohun, T., Mallon, A.-M., Henkelman, R. M., Brown, S. D. M., Adams, D. J., Lloyd, K. C. K., McKerlie, C., Beaudet, A. L., Bućan, M., Murray, S. A., Bućan, M., and Murray, S. A. (2016). High-throughput discovery of novel developmental phenotypes. Nature, 537(7621):508-514.

Domes, G., Heinrichs, M., Kumbier, E., Grossmann, A., Hauenstein, K., and Herpertz, S. C. (2013). Effects of Intranasal Oxytocin on the Neural Basis of Face Processing in Autism Spectrum Disorder. Biological Psychiatry, pages 1-8.

Dorr, A., Lerch, J., Spring, S., Kabani, N., and Henkelman, R. (2008). High resolution three-dimensional brain atlas using an average magnetic resonance image of 40 adult C57Bl/6J mice. NeuroImage, 42(1):60-69.

Dudek, M., Abo-Ramadan, U., Hermann, D., Brown, M., Canals, S., Sommer, W. H., and Hyytiä, P. (2015). Brain activation induced by voluntary alcohol and saccharin drinking in rats assessed with manganese-enhanced magnetic resonance imaging. Addiction Biology, 20(6):1012-1021.

Dudek, M., Canals, S., Sommer, W. H., and Hyytiä, P. (2016). Modulation of nucleus accumbens connectivity by alcohol drinking and naltrexone in alcohol-preferring rats: A manganese-enhanced magnetic resonance imaging study. European Neuropsychopharmacology, 26(3):445-455.

Ecker, . F. . C. and Murphy, C. (2014). Neuroimaging in autism-from basic science to translational research. Nature Publishing Group, 10:82-91.

Elizabeth De Guzman, A., Wong, M. D., Gleave, J. A., and Nieman, B. J. (2016). Variations in post-perfusion immersion fixation and storage alter MRI measurements of mouse brain morphometry. NeuroImage, 142:687-695. 
Ellegood, J., Anagnostou, E., Babineau, B. A., Crawley, J. N., Lin, L., Genestine, M., DiCicco-Bloom, E., Lai, J. K. Y., Foster, J. A., Peñagarikano, O., Geschwind, D. H., Pacey, L. K., Hampson, D. R., Laliberté, C. L., Mills, A. A., Tam, E., Osborne, L. R., Kouser, M., Espinosa-Becerra, F., Xuan, Z., Powell, C. M., Raznahan, A., Robins, D. M., Nakai, N., Nakatani, J., Takumi, T., van Eede, M. C., Kerr, T. M., Muller, C., Blakely, R. D., Veenstra-VanderWeele, J., Henkelman, R. M., and Lerch, J. P. (2015). Clustering autism: using neuroanatomical differences in 26 mouse models to gain insight into the heterogeneity. Molecular Psychiatry, 20(1):118-125.

Ellegood, J., Babineau, B. A., Henkelman, R. M., Lerch, J. P., and Crawley, J. N. (2013). Neuroanatomical analysis of the BTBR mouse model of autism using magnetic resonance imaging and diffusion tensor imaging. NeuroImage, 70:288300 .

Ellegood, J., Petkova, S. P., Kinman, A., Qiu, L. R., Adhikari, A., Wade, A. A., Fernandes, D., Lindenmaier, Z., Creighton, A., Nutter, L. M. J., Nord, A. S., Silverman, J. L., and Lerch, J. P. (2021). Neuroanatomy and behavior in mice with a haploinsufficiency of AT-rich interactive domain 1B (ARID1B) throughout development. Molecular Autism, 12(1):25.

Engelman, J. A., Chen, L., Tan, X., Crosby, K., Guimaraes, A. R., Upadhyay, R., Maira, M., McNamara, K., Perera, S. A., Song, Y., Chirieac, L. R., Kaur, R., Lightbown, A., Simendinger, J., Li, T., Padera, R. F., García-Echeverría, C., Weissleder, R., Mahmood, U., Cantley, L. C., and Wong, K.-K. (2008). Effective use of PI3K and MEK inhibitors to treat mutant Kras G12D and PIK3CA H1047R murine lung cancers. Nature Medicine, 14(12):1351-1356.

Fatemi, S. H., Aldinger, K. A., Ashwood, P., Bauman, M. L., Blaha, C. D., Blatt, G. J., Chauhan, A., Chauhan, V., Dager, S. R., Dickson, P. E., Estes, A. M., Goldowitz, D., Heck, D. H., Kemper, T. L., King, B. H., Martin, L. A., Millen, K. J., Mittleman, G., Mosconi, M. W., Persico, A. M., Sweeney, J. A., Webb, S. J., Welsh, J. P., and Fatemi, H. (2012). Consensus Paper: Pathological Role of the Cerebellum in Autism. Cerebellum, 11(3):777-807.

Galbusera, A., De Felice, A., Girardi, S., Bassetto, G., Maschietto, M., Nishimori, K., Chini, B., Papaleo, F., Vassanelli, S., and Gozzi, A. (2017). Intranasal Oxytocin and Vasopressin Modulate Divergent Brainwide Functional Substrates. Neuropsychopharmacology, 42(7):1420-1434.

Genovese, C. R., Lazar, N. A., and Nichols, T. (2002). Thresholding of Statistical Maps in Functional Neuroimaging Using the False Discovery Rate. NeuroImage, 15(4):870-878.

Gordon, I., Vander Wyk, B. C., Bennett, R. H., Cordeaux, C., Lucas, M. V., Eilbott, J. A., Zagoory-Sharon, O., Leckman, J. F., Feldman, R., and Pelphrey, K. A. (2013). Oxytocin enhances brain function in children with autism. Proceedings of the National Academy of Sciences, 110(52):20953-20958.

Graustella, A. J. and MacLeod, C. (2012). A critical review of the influence of oxytocin nasal spray on social cognition in humans: Evidence and future directions. Hormones and Behavior, 61(3):410-418. 
Green, L., Fein, D., Modahl, C., Feinstein, C., Waterhouse, L., and Morris, M. (2001). Oxytocin and autistic disorder: alterations in peptide forms. Biological Psychiatry, 50(8):609-613.

Gregory, S. G., Connelly, J. J., Towers, A. J., Johnson, J., Biscocho, D., Markunas, C. A., Lintas, C., Abramson, R. K., Wright, H. H., Ellis, P., Langford, C. F., Worley, G., Delong, G. R., Murphy, S. K., Cuccaro, M. L., Persico, A., and Pericak-Vance, M. A. (2009). Genomic and epigenetic evidence for oxytocin receptor deficiency in autism. BMC Medicine, 7(1):62.

Guastella, A. J., Gray, K. M., Rinehart, N. J., Alvares, G. A., Tonge, B. J., Hickie, I. B., Keating, C. M., Cacciotti-Saija, C., and Einfeld, S. L. (2015). The effects of a course of intranasal oxytocin on social behaviors in youth diagnosed with autism spectrum disorders: A randomized controlled trial. Journal of Child Psychology and Psychiatry and Allied Disciplines, 56(4):444-452.

Guastella, A. J. and Hickie, I. B. (2016). Oxytocin Treatment, Circuitry, and Autism: A Critical Review of the Literature Placing Oxytocin Into the Autism Context. Biological Psychiatry, 79(3):234-242.

Harony-Nicolas, H., Kay, M., Du Hoffmann, J., Klein, M. E., Bozdagi-Gunal, O., Riad, M., Daskalakis, N. P., Sonar, S., Castillo, P. E., Hof, P. R., Shapiro, M. L., Baxter, M. G., Wagner, S., and Buxbaum, J. D. (2017). Oxytocin improves behavioral and electrophysiological deficits in a novel Shank3-deficient rat. $E$ Life, 6:e18904.

Hernandez, L. M., Krasileva, K., Green, S. A., Sherman, L. E., Ponting, C., McCarron, R., Lowe, J. K., Geschwind, D. H., Bookheimer, S. Y., and Dapretto, M. (2017). Additive effects of oxytocin receptor gene polymorphisms on reward circuitry in youth with autism. Molecular psychiatry, 22(8):1134-1139.

Hong, S.-J., Valk, S. L., Di Martino, A., Milham, M. P., and Bernhardt, B. C. (2018). Multidimensional Neuroanatomical Subtyping of Autism Spectrum Disorder. Cerebral Cortex, 28(10):3578-3588.

Horev, G., Ellegood, J., Lerch, J. P., Son, Y.-E. E., Muthuswamy, L., Vogel, H., Krieger, A. M., Buja, A., Henkelman, R. M., Wigler, M., and Mills, A. A. (2011). Dosage-dependent phenotypes in models of 16p11.2 lesions found in autism. Proceedings of the National Academy of Sciences, 108(41):17076-17081.

Hrdlicka, M., Dudova, I., Beranova, I., Lisy, J., Belsan, T., Neuwirth, J., Komarek, V., Faladova, L., Havlovicova, M., Sedlacek, Z., Blatny, M., and Urbanek, T. (2005). Subtypes of autism by cluster analysis based on structural MRI data. European Child \& Adolescent Psychiatry, 14(3):138-144.

Huang, H., Michetti, C., Busnelli, M., Managò, F., Sannino, S., Scheggia, D., Giancardo, L., Sona, D., Murino, V., Chini, B., and others (2014). Chronic and acute intranasal oxytocin produce divergent social effects in mice. Neuropsychopharmacology, 39(5):1102-1114. 
Jacob, S., Brune, C. W., Carter, C., Leventhal, B. L., Lord, C., and Cook, E. H. (2007). Association of the oxytocin receptor gene (OXTR) in Caucasian children and adolescents with autism. Neuroscience Letters, 417(1):6-9.

Kosaka, H., Okamoto, Y., Munesue, T., Yamasue, H., Inohara, K., Fujioka, T., Anme, T., Orisaka, M., Ishitobi, M., Jung, M., Fujisawa, T. X., Tanaka, S., Arai, S., Asano, M., Saito, D. N., Sadato, N., Tomoda, A., Omori, M., Sato, M., Okazawa, H., Higashida, H., and Wada, Y. (2016). Oxytocin efficacy is modulated by dosage and oxytocin receptor genotype in young adults with high-functioning autism: a 24-week randomized clinical trial. Translational Psychiatry, 6(8):e872$\mathrm{e} 872$.

Kushki, A., Anagnostou, E., Hammill, C., Duez, P., Brian, J., Iaboni, A., Schachar, R., Crosbie, J., Arnold, P., and Lerch, J. P. (2019). Examining overlap and homogeneity in ASD, ADHD, and OCD: a data-driven, diagnosis-agnostic approach. Translational Psychiatry, 9(1):1-11.

Leng, G. and Ludwig, M. (2016). Intranasal Oxytocin: Myths and Delusions. Biological Psychiatry, 79(3):243-250.

Lerch, J. P., Sled, J. G., and Henkelman, R. M. (2011). MRI Phenotyping of Genetically Altered Mice, volume 711. Humana Press, Totowa, NJ.

Lu, H., Xi, Z.-X., Gitajn, L., Rea, W., Yang, Y., and Stein, E. A. (2007). Cocaineinduced brain activation detected by dynamic manganese-enhanced magnetic resonance imaging (MEMRI). Proceedings of the National Academy of Sciences, 104(7):2489-2494.

Mankiw, C., Park, M. T. M., Reardon, P., Fish, A. M., Clasen, L. S., Greenstein, D., Giedd, J. N., Blumenthal, J. D., Lerch, J. P., Chakravarty, M. M., and Raznahan, A. (2017). Allometric Analysis Detects Brain Size-Independent Effects of Sex and Sex Chromosome Complement on Human Cerebellar Organization. The Journal of Neuroscience, 37(21):5221-5231.

Mathur, B. N. (2014). The claustrum in review. Frontiers in Systems Neuroscience, 8.

McIlwain, K. L., Merriweather, M. Y., Yuva-Paylor, L. A., and Paylor, R. (2001). The use of behavioral test batteries: Effects of training history. Physiology \& Behavior, 73(5):705-717.

Meziane, H., Schaller, F., Bauer, S., Villard, C., Matarazzo, V., Riet, F., Guillon, G., Lafitte, D., Desarmenien, M. G., Tauber, M., and Muscatelli, F. (2015). An Early Postnatal Oxytocin Treatment Prevents Social and Learning Deficits in Adult Mice Deficient for Magel2, a Gene Involved in Prader-Willi Syndrome and Autism. Biological Psychiatry, 78(2):85-94.

Mineur, Y. S., Sluyter, F., de Wit, S., Oostra, B. A., and Crusio, W. E. (2002). Behavioral and neuroanatomical characterization of theFmr1 knockout mouse. Hippocampus, 12(1):39-46. 
Modahl, C., Green, L., Fein, D., Morris, M., Waterhouse, L., Feinstein, C., and Levin, H. (1998). Plasma Oxytocin Levels in Autistic Children. Biol Psychiatry, 43:270-277.

Neumann, I. D., Maloumby, R., Beiderbeck, D. I., Lukas, M., and Landgraf, R. (2013). Increased brain and plasma oxytocin after nasal and peripheral administration in rats and mice. Psychoneuroendocrinology, 38(10):1985-1993.

Nieman, B. J., Lerch, J. P., Bock, N. A., Chen, X. J., Sled, J. G., and Henkelman, R. M. (2007). Mouse behavioral mutants have neuroimaging abnormalities. Human Brain Mapping, 28(6):567-575.

Nieman, B. J., van Eede, M. C., Spring, S., Dazai, J., Henkelman, R. M., and Lerch, J. P. (2018). MRI to Assess Neurological Function. Current Protocols in Mouse Biology, 8(2):e44.

Owada, K., Okada, T., Munesue, T., Kuroda, M., Fujioka, T., Uno, Y., Matsumoto, K., Kuwabara, H., Mori, D., Okamoto, Y., Yoshimura, Y., Kawakubo, Y., Arioka, Y., Kojima, M., Yuhi, T., Yassin, W., Kushima, I., Benner, S., Ogawa, N., Kawano, N., Eriguchi, Y., Uemura, Y., Yamamoto, M., Kano, Y., Kasai, K., Higashida, H., Ozaki, N., Kosaka, H., and Yamasue, H. (2019). Quantitative facial expression analysis revealed the efficacy and time course of oxytocin in autism. Brain, 142(7):2127-2136.

Pagani, M., De Felice, A., Montani, C., Galbusera, A., Papaleo, F., and Gozzi, A. (2020). Acute and repeated intranasal oxytocin differentially modulate brain-wide functional connectivity. Neuroscience, 445:83-94.

Pascual-Leone, A., Freitas, C., Oberman, L., Horvath, J. C., Halko, M., Eldaief, M., Bashir, S., Vernet, M., Shafi, M., Westover, B., Vahabzadeh-Hagh, A. M., and Rotenberg, A. (2011). Characterizing Brain Cortical Plasticity and Network Dynamics Across the Age-Span in Health and Disease with TMS-EEG and TMSfMRI. Brain Topogr, 24:3-4.

PAYLOR, R., SPENCER, C., YUVAPAYLOR, L., and PIEKEDAHL, S. (2006). The use of behavioral test batteries, II: Effect of test interval. Physiology 86 Behavior, 87(1):95-102.

Peñagarikano, O., Lázaro, M. T., Lu, X.-H., Gordon, A., Dong, H., Lam, H. A., Peles, E., Maidment, N. T., Murphy, N. P., Yang, X. W., Golshani, P., and Geschwind, D. H. (2015). Exogenous and evoked oxytocin restores social behavior in the Cntnap2 mouse model of autism. Science Translational Medicine, 7(271):8271.

Perrine, S. A., Ghoddoussi, F., Desai, K., Kohler, R. J., Eapen, A. T., Lisieski, M. J., Angoa-Perez, M., Kuhn, D. M., Bosse, K. E., Conti, A. C., Bissig, D., and Berkowitz, B. A. (2015). Cocaine-induced locomotor sensitization in rats correlates with nucleus accumbens activity on manganese-enhanced MRI HHS Public Access activity in freely behaving animals and to guide new calcium channel-based therapies for treating cocaine abuse and depe. NMR Biomed, 28(11):1480-1488.

Pinheiro, J. and Bates, D. (2000). Mixed-Effects Models in S and S-PLUS. Springer. 
Qiu, L. R., Fernandes, D. J., Szulc-Lerch, K. U., Dazai, J., Nieman, B. J., Turnbull, D. H., Foster, J. A., Palmert, M. R., and Lerch, J. P. (2018). Mouse MRI shows brain areas relatively larger in males emerge before those larger in females. Nature Communications, 9(1):2615.

Quintana, D. S., Rokicki, J., van der Meer, D., Alnæs, D., Kaufmann, T., CórdovaPalomera, A., Dieset, I., Andreassen, O. A., and Westlye, L. T. (2019). Oxytocin pathway gene networks in the human brain. Nature Communications, 10(1):668.

R Core Team (2017). R: A Language and Environment for Statistical Computing.

Rein, B., Tan, T., Yang, F., Wang, W., Williams, J., Zhang, F., Mills, A., and Yan, Z. (2020). Reversal of synaptic and behavioral deficits in a 16p11.2 duplication mouse model via restoration of the GABA synapse regulator Npas4. Molecular Psychiatry.

Richards, K., Watson, C., Buckley, R. F., Kurniawan, N. D., Yang, Z., Keller, M. D., Beare, R., Bartlett, P. F., Egan, G. F., Galloway, G. J., Paxinos, G., Petrou, S., and Reutens, D. C. (2011). Segmentation of the mouse hippocampal formation in magnetic resonance images. NeuroImage, 58(3):732-740.

Robertson, C. E. and Baron-Cohen, S. (2017). Sensory perception in autism.

Sala, M., Braida, D., Lentini, D., Busnelli, M., Bulgheroni, E., Capurro, V., Finardi, A., Donzelli, A., Pattini, L., Rubino, T., Parolaro, D., Nishimori, K., Parenti, M., and Chini, B. (2011). Pharmacologic Rescue of Impaired Cognitive Flexibility, Social Deficits, Increased Aggression, and Seizure Susceptibility in Oxytocin Receptor Null Mice: A Neurobehavioral Model of Autism. Biological Psychiatry, 69(9):875-882.

Saré, R., Figueroa, C., Lemons, A., Loutaev, I., and Beebe Smith, C. (2019). Comparative Behavioral Phenotypes of Fmr1 KO, Fxr2 Het, and Fmr1 KO/Fxr2 Het Mice. Brain Sciences, 9(1):13.

Scholz, J., Niibori, Y., W Frankland, P., and P Lerch, J. (2015). Rotarod training in mice is associated with changes in brain structure observable with multimodal MRI. NeuroImage, 107:182-189.

Sebat, J., Lakshmi, B., Malhotra, D., Troge, J., Lese-Martin, C., Walsh, T., Yamrom, B., Yoon, S., Krasnitz, A., Kendall, J., Leotta, A., Pai, D., Zhang, R., Lee, Y.-H., Hicks, J., Spence, S. J., Lee, A. T., Puura, K., Lehtimaki, T., Ledbetter, D., Gregersen, P. K., Bregman, J., Sutcliffe, J. S., Jobanputra, V., Chung, W., Warburton, D., King, M.-C., Skuse, D., Geschwind, D. H., Gilliam, T. C., Ye, K., and Wigler, M. (2007). Strong Association of De Novo Copy Number Mutations with Autism. Science, 316(5823):445-449.

Silverman, J. L., Yang, M., Lord, C., and Crawley, J. N. (2010). Behavioural phenotyping assays for mouse models of autism. Nature Reviews Neuroscience, 11(7):490-502. 
Sorrells, S. F., Paredes, M. F., Cebrian-Silla, A., Sandoval, K., Qi, D., Kelley, K. W., James, D., Mayer, S., Chang, J., Auguste, K. I., Chang, E. F., Gutierrez, A. J., Kriegstein, A. R., Mathern, G. W., Oldham, M. C., Huang, E. J., GarciaVerdugo, J. M., Yang, Z., and Alvarez-Buylla, A. (2018). Human hippocampal neurogenesis drops sharply in children to undetectable levels in adults. Nature, 555(7696):377-381.

Spencer Noakes, T. L., Henkelman, R. M., and Nieman, B. J. (2017). Partitioning k-space for cylindrical three-dimensional rapid acquisition with relaxation enhancement imaging in the mouse brain. NMR in Biomedicine, 30(11):e3802.

Steadman, P. E., Ellegood, J., Szulc, K. U., Turnbull, D. H., Joyner, A. L., Henkelman, R. M., and Lerch, J. P. (2014). Genetic Effects on Cerebellar Structure Across Mouse Models of Autism Using a Magnetic Resonance Imaging Atlas. Autism Research, 7(1):124-137.

Szulc, K. U., Lerch, J. P., Nieman, B. J., Bartelle, B. B., Friedel, M., Suero-Abreu, G. A., Watson, C., Joyner, A. L., and Turnbull, D. H. (2015). 4D MEMRI atlas of neonatal FVB/N mouse brain development HHS Public Access. Neuroimage, 118:49-62.

Teng, B. L., Nonneman, R. J., Agster, K. L., Nikolova, V. D., Davis, T. T., Riddick, N. V., Baker, L. K., Pedersen, C. A., Jarstfer, M. B., and Moy, S. S. (2013). Prosocial effects of oxytocin in two mouse models of autism spectrum disorders. Neuropharmacology, 72:187-196.

Tsai, P. T., Chu, Y., Greene-Colozzi, E., Sadowski, A. R., Leech, J. M., Steinberg, J., Crawley, J. N., Regehr, W. G., and Sahin, M. (2012). Autistic-like behavior and cerebellar dysfunction in Purkinje cell Tsc1 mutant mice HHS Public Access. Nature, 488(7413):647-651.

Ullmann, J. F., Watson, C., Janke, A. L., Kurniawan, N. D., and Reutens, D. C. (2013). A segmentation protocol and MRI atlas of the C57BL/6J mouse neocortex. NeuroImage, 78:196-203.

van der Plas, E., Spencer Noakes, T. L., Butcher, D. T., Weksberg, R., GalinCorini, L., Wanstall, E. A., Te, P., Hopf, L., Guger, S., Spiegler, B. J., Hitzler, J., Schachar, R. J., Ito, S., and Nieman, B. J. (2020). Quantitative MRI outcomes in child and adolescent leukemia survivors: Evidence for global alterations in gray and white matter. NeuroImage: Clinical, 28:102428.

Vousden, D. (2018). Whole brain imaging of learning, memory, and plasticity. PhD thesis, University of Toronto.

Vousden, D. A., Cox, E., Allemang-Grand, R., Lalibert E, C., Qiu, L. R., Lindenmaier, Z., Nieman, B. J., and Lerch, J. P. (2018). Continuous manganese delivery via osmotic pumps for manganese-enhanced mouse MRI does not impair spatial learning but leads to skin ulceration. NeuroImage, 173:411-420.

Wadghiri, Y. Z., Blind, J. A., Duan, X., Moreno, C., Yu, X., Joyner, A. L., and Turnbull, D. H. (2004). Manganese-enhanced magnetic resonance imaging (MEMRI) of mouse brain development. NMR in Biomedicine, 17(8):613-619. 
Watanabe, T., Abe, O., Kuwabara, H., Yahata, N., Takano, Y., Iwashiro, N., Natsubori, T., Aoki, Y., Takao, H., Kawakubo, Y., Kamio, Y., Kato, N., Miyashita, Y., Kasai, K., and Yamasue, H. (2014). Mitigation of Sociocommunicational Deficits of Autism Through Oxytocin-Induced Recovery of Medial Prefrontal Activity. JAMA Psychiatry, 71(2):166.

Watanabe, T., Kuroda, M., Kuwabara, H., Aoki, Y., Iwashiro, N., Tatsunobu, N., Takao, H., Nippashi, Y., Kawakubo, Y., Kunimatsu, A., Kasai, K., and Yamasue, H. (2015). Clinical and neural effects of six-week administration of oxytocin on core symptoms of autism. Brain, 138(11):3400-3412.

Wheeler, A. L., Lerch, J. P., Chakravarty, M. M., Friedel, M., Sled, J. G., Fletcher, P. J., Josselyn, S. A., and Frankland, P. W. (2013). Adolescent Cocaine Exposure Causes Enduring Macroscale Changes in Mouse Brain Structure. Journal of Neuroscience, 33(5):1797-1803.

Yang, M., Bozdagi, O., Scattoni, M. L., Wohr, M., Roullet, F. I., Katz, A. M., Abrams, D. N., Kalikhman, D., Simon, H., Woldeyohannes, L., Zhang, J. Y., Harris, M. J., Saxena, R., Silverman, J. L., Buxbaum, J. D., and Crawley, J. N. (2012). Reduced Excitatory Neurotransmission and Mild Autism-Relevant Phenotypes in Adolescent Shank3 Null Mutant Mice. Journal of Neuroscience, 32(19):6525-6541.

Yatawara, C. J., Einfeld, S. L., Hickie, I. B., Davenport, T. A., and Guastella, A. J. (2016). The effect of oxytocin nasal spray on social interaction deficits observed in young children with autism: a randomized clinical crossover trial. Molecular Psychiatry, 21(9):1225-1231.

Zhang, T.-Y., Keown, C. L., Wen, X., Li, J., Vousden, D. A., Anacker, C., Bhattacharyya, U., Ryan, R., Diorio, J., O'Toole, N., Lerch, J. P., Mukamel, E. A., and Meaney, M. J. (2018). Environmental enrichment increases transcriptional and epigenetic differentiation between mouse dorsal and ventral dentate gyrus. Nature Communications, 9(1):298. 